\title{
Unsere Vorfahren
}

\author{
Crashkurs und Update
}

Korrespondenzadresse

Prof. Dr. Dr. Manfred Spitzer

Universität Ulm

Leimgrubenweg 12-14

87054 Ulm, Deutschland
Bibliografie

Nervenheilkunde 2021; 40: 492-510

DOI 10.1055/a-1389-6941

ISSN 0722-1541

(C) 2021. Thieme. All rights reserved.

Georg Thieme Verlag KG, Rüdigerstraße 14,

70469 Stuttgart, Germany

\section{Zusammenfassung}

Noch vor etwa 20 Jahren stellte man sich die Entstehung des Menschen als eine relativ gradlinige Entwicklung vor, die mit dem gemeinsamen Vorfahren von uns und den Schimpansen vor etwa 7 Millionen Jahren begann und mit uns, dem Homo sapiens aufhörte. Dem ist nicht so, wie Funde aus dem letzten halben Jahrhundert und groß angelegte Untersuchungen und Vergleiche von Genen vieler heutiger Menschen, sowie einiger historischer und prähistorischer Menschen, in den vergangenen 10 Jahren zeigten. Vor 4-2 Millionen Jahren gab es affenartige Wesen, die Australopithecine (Singular: Australopithecus) und vor 2,5 Millionen Jahren die ersten Vertreter der Gattung Mensch (Homo). Bis 2 Millionen Jahre reicht das Alter der Funde von Homo erectus zurück, dessen Gehirnvolumen im Laufe von mehr als einer Million Jahren dann von $800 \mathrm{~cm}^{3}$ auf $1200 \mathrm{~cm}^{3}$ zunahm und der dem modernen Menschen schon sehr ähnlich war. Vor 2 Millionen Jahren verbreitete er sich aus Afrika heraus nach Europa und Asien, wo der Neandertaler (in Europa) und der Denisovan-Mensch (in Asien) sich aus ihm vor etwa 400000 Jahren entwickelt hatten. Vor etwa 200000 Jahren entstand aus Homo erectus in Afrika Homo sapiens und wanderte vor etwa 50000 Jahren nach Europa und Asien. Diese 3 Gruppen zeugten Nachkommen miteinander, sodass die Gene des $\mathrm{Ne}$ andertalers vor allem in Europa und die des Denisovaners vor allem in Asien noch heute in der Bevölkerung zu finden sind. Durch genetische Analysen gelang innerhalb des vergangenen Jahrzehnts die Rekonstruktion der Ausbreitung des heutigen Menschen in einem noch vor 20 Jahren unvorstellbarem Detailreichtum. Die Konsequenzen dieser Erkenntnisse reichen mittlerweile bis hinein in die personalisierte Medizin und werden uns noch lange beschäftigen.

Die Paläontologie (altgriechisch palaiós: „alt“, óntos: „seiend“ und logos: „Wort“) ist die „Wissenschaft vom alten Kram“, den man ausgräbt (lateinisch fossilis: „ausgegraben“) und bei dem es sich um die körperlichen Überreste von Pflanzen und Lebewesen sowie sonstige Zeugnisse (z. B. Fußspuren) handelt. Diese Wissenschaft von allem, was älter ist als 10000 Jahre, ist mit etwa 150 Jahren selbst vergleichsweise jung, denn die Geschichtsschreibung, die sich auf die Zeit danach bezieht, gibt es schon seit etwa 2500 Jahren. Die Paläoanthropologie untersucht die Entstehung des Men- schen im Laufe der Evolution, ausgehend von, und eingebettet in, die Evolution der Primaten. Mit Antworten auf die Frage „Wie entstanden wir?“ trägt sie zum Selbstverständnis des Menschen bei, also zur Frage „Wer sind wir?“ [37]. Zahlreiche neue Fossilienfunde und vollkommen neue Untersuchungsmethoden aus anderen Wissenschaften haben zu erheblichen Fortschritten, komplexen Überlegungen und einer Vielzahl neuer Erkenntnisse geführt.

Insbesondere die Genetik und die Möglichkeit der genetischen Untersuchung von Fossilien, prähistorischen und historischen Menschen aus Gräbern, sowie die breite Untersuchung des Genoms von Menschen weltweit haben zu überraschenden Erkenntnissen geführt. Wenn kein Erbgut mehr zu finden ist, kann die Analyse von Proteinen in oder an fossilen Zähnen und Knochen noch weiteren Erkenntnisse liefern und die Daten ergänzen. Mittlerweile gelang es sogar, Archäologie ohne Funde, also buchstäblich nur mit „Dreck“ aus bekannten Fundstellen von Fossilien zu betreiben [88, 104]. Durch die Analysen von aDNA (ancient DNA) unserer nächsten Verwandten und historischer Vorfahren wurde es im vergangenen Jahrzehnt möglich, den Stammbaum und die Verbreitung des heutigen Menschen in einem nie dagewesenen Detailreichtum zu beschreiben [49, 73, 95].

\section{Australopithecus: Der „südliche Affe“}

Vor 7-8 Millionen Jahren ${ }^{1}$ lebte in Afrika der gemeinsame Vorfahre von Menschen und den heutigen Schimpansen (Gattung Pan, bestehend aus den Arten Schimpanse und Zwergschimpanse, auch Bonobo genannt; Abb. 1). Aus ihm heraus entwickelten sich Vormenschen, die vor etwa 4-2 Millionen Jahren lebten. Das erste Skelett von ihnen wurde im Jahr 1925 gefunden. Man bezeichnete sie als Australopithecus, was (aus dem Altgriechischen) übersetzt „südlicher Affe“ bedeutet. Deren Name ist so schwer auszusprechen, dass viele einfach nur von „Lucy“ reden. Die Größe (ca. $130 \mathrm{~cm}$ ) und Form (längere Arme, kürzere Beine) von Australopithecus lag irgendwo zwischen Affe und Mensch ( $>$ Abb. 3). Ihre

1 Man sprach früher immer von 5-7 Millionen Jahren, jedoch genauere Untersuchungen zu Generationszeiten legen einen etwas älteren SplitPunkt nahe [52]. 


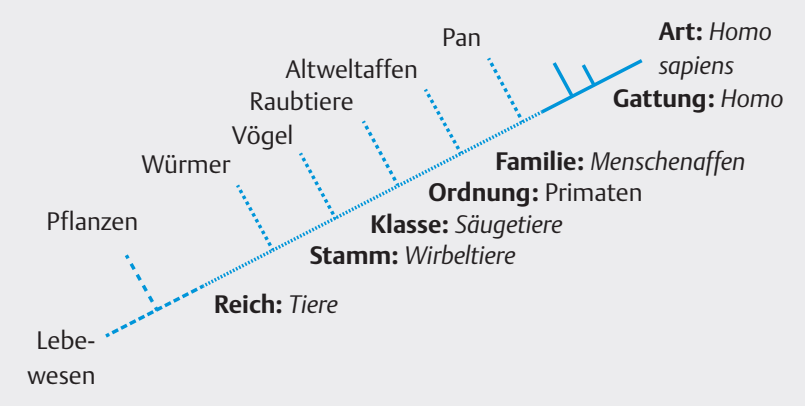

- Abb. 1 Übersicht zur Evolution bis zum Auftreten der Gattung Homo vor gut 2,5 Millionen Jahren. Von links unten nach rechts oben verläuft (nicht im linearen Maßstab) die Zeit, aber vor allem auch die zunehmende Genauigkeit der begrifflichen Einordnung (ein Reich enthält viele Stämme, diese wiederum viele Klassen, diese viele Ordnungen usw.). Oberhalb der schrägen Linie sind jeweils Alternativen zu den fett gedruckten systematischen Begriffen bzw. weitere Repräsentanten der kursiv gedruckten Begriffe angegeben, um die Orientierung zu erleichtern. Hinter den fett gedruckten Allgemeinbegriffen ist die Hierarchie der Einordnung des Menschen mit den entsprechenden Begriffen systematisiert. So gehört die Familie der Altweltaffen - neben den Menschenaffen - zur Ordnung der Primaten. Zur Gattung Pan gehören die Schimpansen und die Zwergschimpansen (Bonobos).

Vielfalt wurde mittlerweile einer ganzen Reihe von (allesamt ausgestorbenen) Arten zugeordnet, und so spricht man vom Australopithecus afarensis, africanus, anamensis, bahrelghazali, deyiremeda, garhi und sediba $[84,108]$.

Der unter dem Namen „Lucy“ bekannteste Fund - im heutigen Äthiopien - stammt aus dem Jahr 1974. Es handelt sich wahrscheinlich um ein gerade einmal $107 \mathrm{~cm}$ großes, etwa 25 Jahre altes weibliches Individuum der Art Australopithecus afarensis, das vor 3,2 Millionen Jahren lebte. Nach der Form des Skeletts, vor allem der Arme, Beine und Füße und nach dem Fund von 3,6 Millionen Jahre alten fossilen Fußspuren bei Laetoli im Norden von Tansania, die ebenfalls Australopithecus afarensis zugeschrieben wurden [53], geht man davon aus, dass Lucy einerseits schon aufrecht ging wie die heutigen Menschen, andererseits aber dennoch viel Zeit in Bäumen verbracht haben muss, weil ihre Arme vergleichsweise kräftig waren und sich gut zum Hangeln eigneten [77].

\section{Homo - die ersten Menschen}

Zur Gattung „Mensch“ (Homo) gehört der 1960 im heutigen Tansania entdeckte Homo habilis ( lis“ bedeutet „begabt“ bzw. „geschickt“, und diese Bezeichnung wurde gewählt, weil es sich einerseits zwar um einen noch sehr kleinen (Körpergröße: 1-1,2 Meter) und evolutionär sehr frühen Menschen handelte (vor 2,3 Millionen Jahren), bei dem jedoch erstmalig der Gebrauch von Steinwerkzeugen vorlag. Mit dem Werkzeuggebrauch, den man schon von anderen Funden her kannte, wurde die neue Gattung „Mensch“ gerechtfertigt.

Schon vor 2,5-2,3 Millionen Jahren, also noch früher als der Homo habilis lebte der Homo rudolfensis, der allerdings erst im Jahr 1991 im heutigen Malawi entdeckt bzw. gefunden wurde [118, 119]. Er war mit einer Körpergröße von 1,3-1,5 Metern deutlich

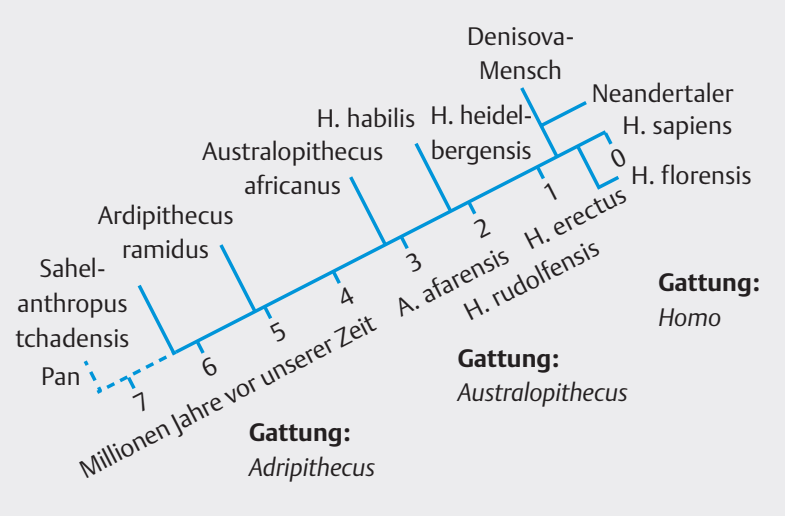

Abb. 2 Übersicht zur Evolution des heutigen Menschen im Lauf der vergangenen 7-8 Millionen Jahre. Von links unten nach rechts oben verläuft die Zeit (keine zunehmende begriffliche Spezialisierung). Vieles ist noch im Fluss: Ob die Gattung Sahelanthropus (deren Vertreter Sahelanthropus tchadensis hier ganz links aufgeführt ist) zu unseren Vorfahren gehört, wird diskutiert. Ardipithecus ist eine von Tim White und Mitarbeitern im Jahr 1994 erstmals beschriebene Gattung der Primaten aus der Familie der Menschenaffen (in der Erstbeschreibung noch der Gattung Australopithecus zu geordnet; von den gleichen Autoren ein Jahr später in einem Corrigendum als neue Gattung bezeichnet), die vor rund 6-4 Millionen Jahren in Äthiopien gelebt hat [106]. Die Art Ardipithecus ramidus (hier ebenfalls als Seitenlinie dargestellt) gehört möglicherweise auch zu unseren ältesten bekannten direkten Vorfahren, Australopithecus africanus und Homo habilis dagegen nach gegenwärtigem Stand nicht.

größer als der Homo habilis und besaß auch ein größeres Hirnvolumen. Nach Körpergröße, Gehirngröße und Alter würde man heute Homo rudolfensis als den ersten Vertreter der Gattung Homo betrachten, denn er lebte früher und erscheint weiter entwickelt gewesen zu sein als Homo habilis. Da bei ihm allerdings bislang kein Werkzeuggebrauch nachgewiesen wurde (und dieser das Kriterium für die Gattung Homo darstellte), passen die Teile dieses Puzzles noch nicht genau zusammen. Dennoch lässt sich mit ziemlicher Sicherheit sagen, dass die Gattung Mensch in Afrika vor 2,5 Millionen Jahren entstanden war.

\section{Homo erectus}

Beim Homo erectus handelt es sich um eine ausgestorbene Art der Gattung Homo, aus der sich unsere Vorfahren in Europa, Asien und Afrika getrennt voneinander entwickelten [1]. Die ältesten Funde stammen aus Afrika und sind 2 Millionen Jahre [39]. Homo erectus lebte über einen sehr langen Zeitraum bis zuletzt auf Java vor gut 100000 Jahren [75]. Wie in $\mathbf{A b b .} \mathbf{3}$ zu sehen, war er dem heutigen Menschen (Homo sapiens) mit einer Körpergröße von 1,7 Metern und einem Gehirnvolumen, das sich über Jahrhunderttausende von 800-1200 cm³ entwickelte, schon sehr ähnlich. Wie der Name sagt, ging er aufrecht auf 2 vergleichsweise langen Beinen [5], konnte auch rennen und lebte unter anderem von der Jagd. Die Anatomie der Schulter des aufrechten Menschen ermöglichte den Speerwurf. Er kooperierte dabei mit Artgenossen, musste daher auch über höhere, d. h. komplexere soziale Fähigkeiten verfügen und wahrscheinlich auch über eine einfache Sprache. Auch 


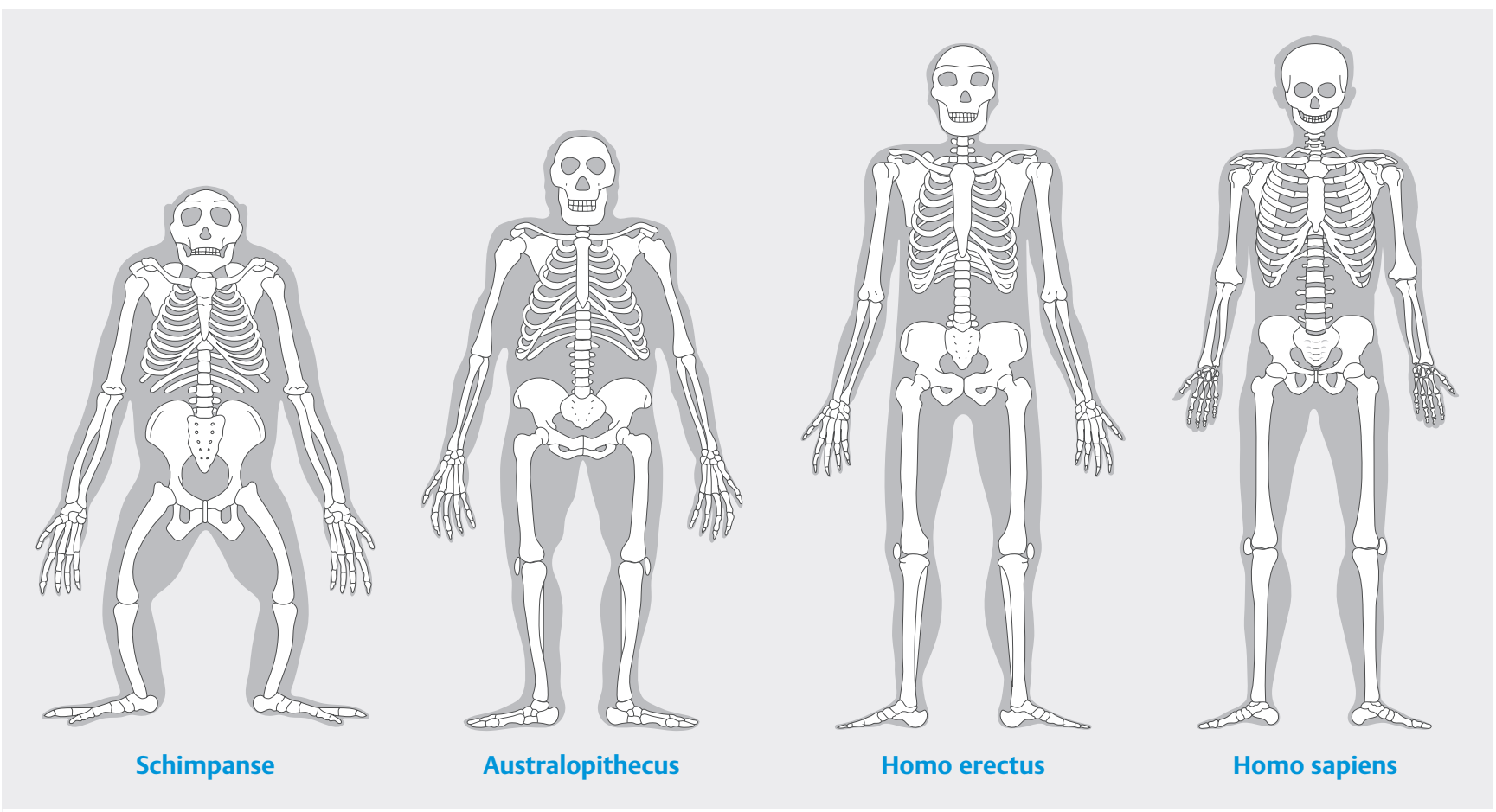

- Abb. 3 Gegenüberstellung des Körperbaus des heutigen Schimpansen (dessen mit uns gemeinsamer Vorfahre vor 7 Millionen Jahren lebte), mit dem Körperbau von Australopithecus (ausgestorben, lebte vor 4 bis vor 2 Millionen Jahren) und Homo erectus (ausgestorben, lebte vor 2 Millionen bis vor 70000 Jahren) sowie des seit 200000 Jahren die Erde bevölkernden Homo sapiens (nach Daten aus [116]).

seine Werkzeuge waren komplexer als die von Homo habilis. Aufgrund seiner körperlichen, psychischen und sozialen Fähigkeiten verbreitete Homo erectus (bzw. sein unmittelbarer Vorläufer) beginnend vor etwa 2 Millionen Jahren die Gattung Mensch aus Afrika heraus nach Europa und Asien ( $\bullet$ Abb. 4).

In Europa stammte von ihm zunächst der Homo heidelbergensis (vor 800000 bis vor 400000 Jahren) ab, aus dem heraus sich ab vor etwa 500000 Jahren der Neandertaler in Europa entwickelte. Deutlich früher geschah in Asien unabhängig davon die Entwicklung eines nach neuen Erkenntnissen sehr weit verbreiteten Menschen, des Denisovaners, beginnend vor etwa 850000 Jahren, auch aus Homo erectus heraus, und unabhängig von Europa. In Indonesien entwickelten sich aus ihm auf den Inseln Flores und Luzon der Homo floresiensis, ein Zwergmensch, der erst vor etwa 50000 Jahren ausstarb, und der Homo luzonensis. In Afrika entstanden aus dem Homo erectus unsere direkten Vorfahren, der Homo sapiens $(\triangleright$ Tab. 1), wobei es auch dort weitere „Nebenlinien“ gab (Homo naledi).

Im Jahr 2001 wurde in Dmanisi im heutigen Georgien ein 1,8 Millionen Jahre alter Schädel mit Unterkiefer gefunden, der eigentlich nach Afrika gehört hätte. Mit einem Gehirnvolumen von $600 \mathrm{~cm}^{3}$ steht er zwischen Homo habilis bzw. Homo rudolfensis und dem Homo erectus, dessen erstes Auftreten in Afrika 200000 Jahre älter ist als der Homo georgicus, wie er seit dem Jahr 2002 genannt wird. Er steht also entwicklungsgeschichtlich zwischen 2 Arten, die in Afrika lebten, war aber (schon) nach Kleinasien gewandert. Der Fund könnte bedeuten, dass Homo erectus sich schon auf Wanderschaft befand ( $\bullet$ Abb. 4 ) oder sogar, dass Homo habilis bzw. rudolfensis bereits zuvor, also vor mehr als 2 Millionen Jahren Afrika verlassen hatten, „sich in Westasien zu Homo erectus [entwickel- ten] und vor weniger als 2 Millionen Jahren als ebendieser wieder nach Ostafrika [zurück einwanderte]", wie Sandrock und Schrenk [78] formulieren. Mit jedem neuen Fund werden zwar manche Fragen geklärt, vor allem jedoch wird die Geschichte ${ }^{2}$ komplizierter.

Fest steht, dass Homo erectus schon vor 1,6-1,7 Millionen Jahren in Asien und Indonesien angekommen war. Homo erectus-Funde aus dem frühen 20. Jahrhundert (,Java-Mensch“, „Peking-Mensch“) führten daher auch zur These, dass der Mensch in Asien entstanden sei (Out of Asia hypothesis). Gemäß der Out-of-Africa-Hypothese kam es dagegen vor etwa 50000 Jahren zu einer Verbreitung des Homo sapiens aus Afrika heraus, über den Nahen Osten (den „fruchtbaren Halbmond“; $>$ Abb.5) nach Europa und Asien. So wundert auch nicht, dass man die ältesten unter unseren direkten Vorfahren in dieser Gegend vermutet. Mittlerweile konnte genetisch nachgewiesen werden, dass auf der arabischen Halbinsel und um sie herum die Nachkommen der frühesten Abspaltung vom europäischen Menschen wohnen [76]. Ihr Genom enthält daher mit 2,6\% einen eher geringen Neandertaler-Anteil.

Was stimmt nun: „Out of Asia“ oder „Out of Africa“? - Beides oder nichts davon, denn es war vor allem eines: noch komplizierter.

\section{Homo heidelbergensis}

Im Jahr 1907 wurde ein Unterkiefer in einer Kiesgrube im Ort Mauer am Flüsschen Elzenz (mündet 10 km flussaufwärts von Heidelberg in den Neckar) gefunden, der zusammen mit einer ganzen Reihe weiterer Funde aus anderen europäischen Ländern (Frankreich, Gi-

2 "Geschichte“ meint hier ganz bewusst sowohl das, was man heute gern als „Narrativ" bezeichnet, als auch „Historie“. 


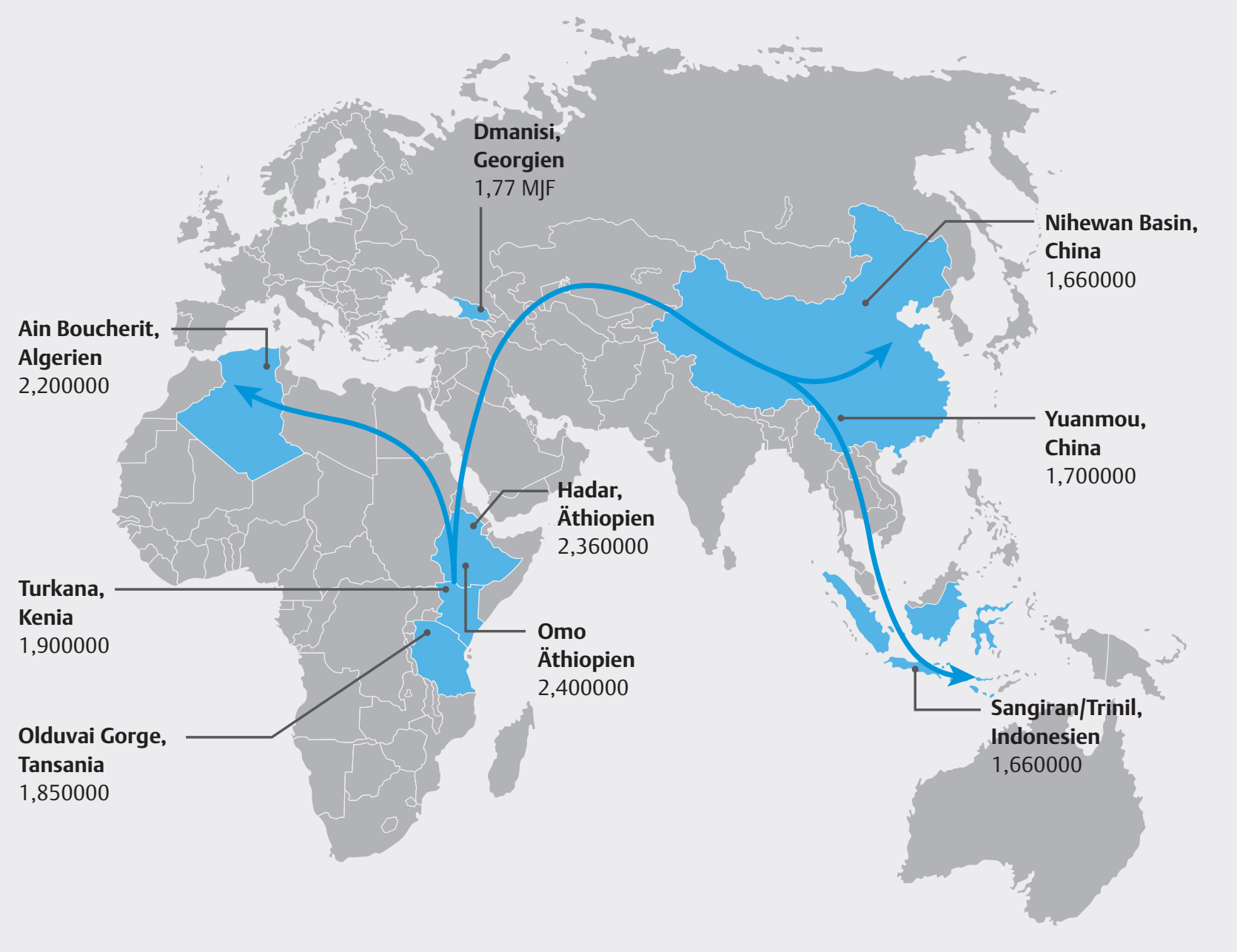

- Abb. 4 Der Homo erectus (bzw. sein unmittelbarer Vorläufer) wanderte buchstäblich bis ans Ende der Welt. Angegeben sind die Namen der Fundorte und die Datierung der Funde vor der Jetztzeit (nach Daten aus [28]).

braltar, Griechenland, Italien, Spanien, Südengland) als Homo heidelbergensis bezeichnet wird. Dieser lebte vor 800000-400 000 Jahren und war mit einem Gehirnvolumen von $1400 \mathrm{~cm}^{3}$ und einer Körpergröße von 1,6-1,7 m uns heutigen Menschen schon sehr ähnlich. Er jagte in kleinen Gruppen mit hölzernen Speeren [20, 99, 100] auch größere Tiere (Wildkatzen, Pferde, Großwild) und begrub die Toten, auch mit Grabbeigaben. Die in diesem Text ( $\triangleright$ Tab. 1) angeführten Zeiten können nur Näherungswerte darstellen, denn nichts in der Evolution geschieht in einem Augenblick. Damit vor 400000 Jahren Neandertaler in Europa und Denisovaner in Asien leben konnten, mussten sie sich vorher entwickelt und vom Homo heidelbergensis sowie voneinander getrennt haben. Dies bedeutet jedoch nicht, dass sich ihre Verbreitungsgebiete später nicht wieder überlappten und es damit zu Kontakten kam.

Mittlerweile wurde eine ganze Reihe von Homo-heidelbergensis-Funden über ganz Europa hinweg - neben Deutschland (in Baden-Württemberg: Reilingen, Steinheim an der Murr; in Thüringen: Bilzingsleben, Ehringsdorf) in Spanien, Frankreich, Ungarn, Italien, Griechenland sowie in Israel und Marokko - beschrieben [16, 120]. In Südengland beispielsweise wurde 1993 in Boxgrove, West Sussex, nahe der Südküste Englands, vom Archäologen Mark Roberts und seinem Team vom Institute of Archaeology am University Col- lege London ein 500000 Jahre altes Fossil entdeckt, das Homo heidelbergensis zugeordnet wird [92]. Vom Boxgrove Man, dem bislang ältesten menschlichen Fossil, das jemals in Großbritannien entdeckt wurde, gibt es nur 2 Stücke der Tibia (Schienbein) und 2 Zähne. Man weiß sehr wenig über diesen Mann, bei dem nicht einmal ausgeschlossen werden kann, dass es sich um eine stark gebaute Frau (ungefähr 40 Jahre alt, 1,8 Meter groß) handelt.

\section{Exkurs: Paläogenetik}

Die Paläogenetik, ein mit etwa 35 Jahren recht junges Teilgebiet der Genetik, befasst sich mit der genetischen Information verstorbener Lebewesen, was sowohl durch die Analyse genetischer Proben aus Funden erfolgt als auch durch Rekonstruktion genetischer Informationen aus der Vergangenheit mittels Daten von lebenden Organismen. Anders als der Name suggeriert, kann es sich bei den Funden sowohl tatsächlich um Fossilien aus der Steinzeit handeln, aber auch um prähistorische oder historische Überreste jüngerer Zeit (von „Özi“ und Mumien über mittelalterliche und sogar neuzeitliche Gräber). Im Jahr 1984 wurde erstmals anhand einer Museumsprobe die Sequenz der mitochondrialen DNA aus getrockneter Skelettmuskulatur einer 1883 ausgerotteten Zebra-Art (genannt 
- Tab. 1 Biologische Merkmale unserer Vorfahren.

\begin{tabular}{|c|c|c|c|c|}
\hline Wer & Wann (Alter in Jahren) & Wo & Gehirnvolumen $\left(\mathrm{cm}^{3}\right)$ & Wesentliche Merkmale \\
\hline Australopithecus & 4-2 Millionen & Afrika & $400-550$ & $\begin{array}{l}\text { Erstmals aufrechter Gang, lange Arme, Pflanzen } \\
\text { als Nahrung, große Backenzähne und Kaumuskeln, } \\
\text { Schlaf auf Bäumen; mit 110-130 cm relativ klein }\end{array}$ \\
\hline $\begin{array}{l}\text { Homo (oder } \\
\text { Australopithecus) habilis }\end{array}$ & 2,3-1,6 Millionen & Afrika & $600-700$ & $\begin{array}{l}\text { Erstmals Gebrauch einfacher Werkzeuge; Oppositi- } \\
\text { on des Daumens; mit 100-120 cm relativ klein }\end{array}$ \\
\hline Homo rudolfensis & 2,8-1,8 Millionen & Afrika & $700-750$ & $\begin{array}{l}\text { Mit } 130-150 \mathrm{~cm} \text { deutlich größer als Australopithe- } \\
\text { cus }\end{array}$ \\
\hline Homo georgicus & 1,8 Millionen Jahre & Georgien & 600 & $\begin{array}{l}\text { Ältester Fund eines Vertreters der Gattung Homo } \\
\text { außerhalb Afrikas. }\end{array}$ \\
\hline Homo erectus & 2 Millionen-70000 & Afrika, Asien & $800-1200$ & $\begin{array}{l}\text { Existierte von allen Arten der Gattung Homo am } \\
\text { längsten (knapp } 2 \text { Millionen Jahre); } 140-180 \mathrm{~cm} \\
\text { groß; nutzte das Feuer, ernährte sich auch von } \\
\text { Fleisch }\end{array}$ \\
\hline Homo heidelbergensis & $800000-400000$ & $\begin{array}{l}\text { Mitteleuropa, } \\
\text { Nordafrika, } \\
\text { naher Osten }\end{array}$ & $1100-1400$ & $\begin{array}{l}\text { Neben Steinwerkzeugen auch Holzspeere zur Jagd } \\
\text { von größeren Tieren; erste Grabbeigaben; } 160 \mathrm{~cm} \\
\text { groß, in Gruppen lebend }\end{array}$ \\
\hline Homo neanderthalensis & $400000-30000$ & $\begin{array}{l}\text { Europa, } \\
\text { West- und } \\
\text { Zentralasien }\end{array}$ & $1200-1750$ & $\begin{array}{l}160 \text { cm groß; Holzspeere mit Steinspitzen, durch } \\
\text { Birkenpech befestigt; Feuer diente damit auch zur } \\
\text { Werkzeugherstellung. Jagd von größeren Tieren } \\
\text { (Mammuts, Bären, Nashörner); vielfältige Nahrung; } \\
\text { Kleidung (Tierfelle) gegen Kälte; Bestattung von } \\
\text { Toten, Grabbeigaben }\end{array}$ \\
\hline Denisovan-Mensch & $400000-30000$ & Asien & unbekannt & $\begin{array}{l}\text { Große Backenzähne, wahrscheinlich auch größer als } \\
\text { H. sapiens; Schmuck }\end{array}$ \\
\hline Homo floresiensis & bis 60000 & $\begin{array}{l}\text { Flores, } \\
\text { Indonesien }\end{array}$ & 417 & $\begin{array}{l}\text { Bemerkenswert kleiner (etwa } 1 \text { Meter) Vertreter } \\
\text { der Gattung Homo. Einfache Steinwerkzeuge, } \\
\text { jagte zwergwüchsige Verwandte des Elefanten } \\
\text { (Stegodon) }\end{array}$ \\
\hline Homo luzonensis & vor 67000 & $\begin{array}{l}\text { Luzon, } \\
\text { Indonesien }\end{array}$ & unbekannt & $\begin{array}{l}\text { Ähnlich wie Homo florensis, kleinere Zähne als } \\
\text { Homo sapiens, Anpassungen an das Leben auf } \\
\text { Bäumen }\end{array}$ \\
\hline Homo sapiens & 200000 bis heute & weltweit & 1450 & $\begin{array}{l}\text { Gesellschaften, Kultur, Wissenschaft. Älteste } \\
\text { Grabstätte in Afrika vor } 78300 \text { Jahren; älteste } \\
\text { Schmucksteinsammlung vor } 105000 \text { Jahren; ältes- } \\
\text { ter Körperschmuck vor } 75000 \text { Jahren }\end{array}$ \\
\hline
\end{tabular}

„Quagga“) publiziert. Die Autoren dieser Arbeit beendeten ihre Arbeit mit dem Satz: „Sollte es sich herausstellen, dass DNA ganz allgemein lange Zeit überdauern kann, dürften so unterschiedliche Wissensgebiete wie die Paläontologie, Evolutionsbiologie, Archäologie und Forensik davon profitieren“3 [40]. Ein Jahr später veröffentlichte Svante Pääbo, der das Fachgebiet mittlerweile über mehr als zweieinhalb Jahrzehnte wie kein anderer geprägt hat und zuweilen als Begründer der Paläogenetik bezeichnet wird, eine Arbeit über die Isolierung und Klonierung von DNA aus einer 2400 Jahre alten ägyptischen Kindermumie aus dem Berliner Pergamon-Museum. Er musste Material von 23 Mumien auswerten, um bei einer von ihnen mit einem DNA-Strang von 3400 Basen fündig zu werden. Am Ende dieser Arbeit spricht der Autor davon, dass die Ergebnisse zur Hoffnung Anlass geben, systematisch auf archäologische Funde übertragen werden zu können [62].

3 „If the long-term survival of DNA proves to be a general phenomenon, several fields including palaeontology, evolutionary biology, archaeology and forensic science may benefit."
Das Wort „Paläogenetik“ und die Idee dahinter und sind älter als die genannten Publikationen und gehen zurück auf einen Artikel des Doppelnobelpreisträgers Linus Pauling (1901-1994) und des Evolutionsbiologen Emile Zuckerkandl (1922-2013), der schon im Jahr 1963 publiziert worden war [65]. Dort deklinieren die beiden Autoren nicht nur den Gedanken am Fall des menschlichen Hämoglobins und dessen vermutlicher evolutionärer Entstehung durch, sondern entwerfen gleich die ganze Wissenschaft in beeindruckender seherischer Klarheit. Man werde nicht nur Gene in Fossilien untersuchen können, sondern diese auch anhand der Gene lebender Organismen rekonstruieren können. Dann werde man diese Gene und deren Genprodukte synthetisieren, um daraus Rückschlüsse auf die Lebensbedingungen und die Lebensweisen nicht mehr lebender Organismen zu ziehen. „Sofern ein Fossilienbestand vorhanden ist, wird das Wissen über die Organismen weit über das hinausgehen, was bisher für möglich gehalten wurde. Wir werden sogar bedeutsame Informationen zu Lebensformen erhalten, von denen 


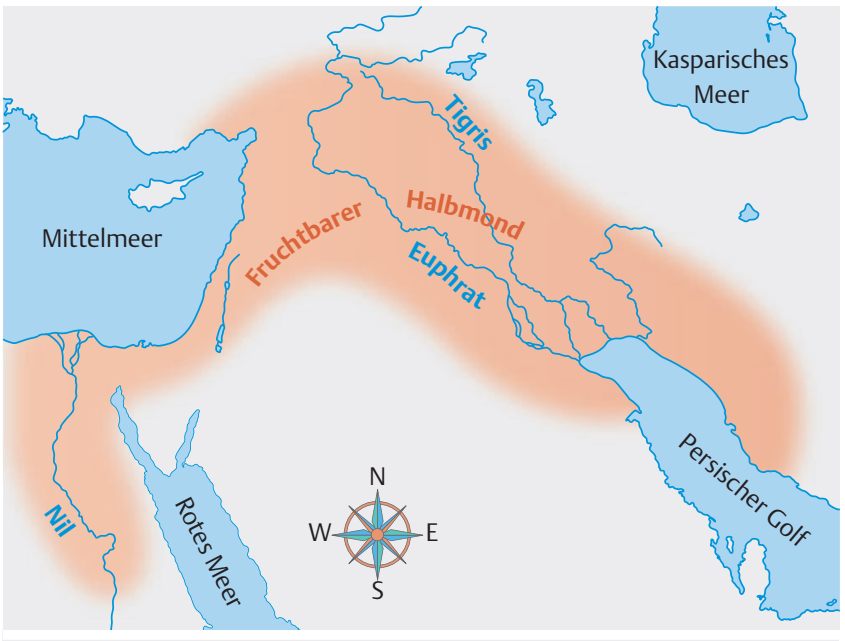

- Abb. 5 Man spricht so oft vom Fruchtbaren Halbmond, aber wo der genau ist und warum er so heißt, ist den Wenigsten geläufig. Die Sichel "liegt“" mit ihren Spitzen am Nil und am Persischen Golf, wie ein umgekehrtes „u“, dessen Bogen die südliche Türkei streift.

es keinerlei Fossilien gibt..."4 , schreiben die Autoren [65, S. 15] über die Paläogenetik 20 Jahre bevor es diese Wissenschaft überhaupt gab. Wie recht sie mit ihrer Prognose hatten, begann sich in den 1980er-Jahren zu zeigen. Damals begannen Wissenschaftler damit, kein geringeres Problem zu lösen als das von Eva und Adam.

\section{Eva und Adam}

Anfang der 1980er-Jahre war das gesamte menschliche Genom noch längst nicht entschlüsselt. Durch die Analyse von Unterschieden bei einzelnen Genen sowie durch die Entschlüsselung der menschlichen mitochondrialen DNA gelangte man damals jedoch bereits zu erstaunlichen Entdeckungen. Die Mitochondrien - die „Kraftwerke“ in allen tierischen Zellen ${ }^{5}$ - haben ihr eigenes Genom, d. h. ihr genetischer Bauplan ist nicht im Zellkern, sondern in den Mitochondrien selbst (d. h. in einem Typus von Organellen) in den Körperzellen vorhanden. Eine Zelle in der Leber beispielsweise enthält etwa 500-2000 Mitochondrien, je nachdem, wie viel Energie gerade gebraucht wird. So können diese Organellen zwischen $20 \%$ und $80 \%$ des Gesamtzellvolumens ausmachen. Die mitochondriale DNA (mtDNA) ist zwar klein (16569 Basenpaare kodieren 13 Proteine), aber in vergleichsweise größeren Mengen in jeder Körperzelle vorhanden als das übrige nur im Zellkern gespei-

4 „When a fossil record is available, knowledge about the organisms will go far beyond what so far has been believed possible. Important informationwill also be provided about forms hat have left no fossil record whatsoever..."

5 Mitochondrien waren wahrscheinlich früher frei lebende Bakterien, die von mehr als einer Milliarde Jahren von Zellen aufgenommen wurden und seither in einer Symbiose mit ihnen leben. Im Gegensatz zur üblichen Symbiose (was übersetzt „Zusammenleben“ heißt), bilden die Mitochondrien keine Gemeinschaft, sondern leben als „Endosymbionten" in ihnen. Dies hat in der langen evolutionären Entwicklung dieser Symbiose dazu geführt, dass die Zelle einige Stoffwechselfunktionen des Bakteriums übernommen hat, das für sich allein nicht mehr lebensfähig wäre.

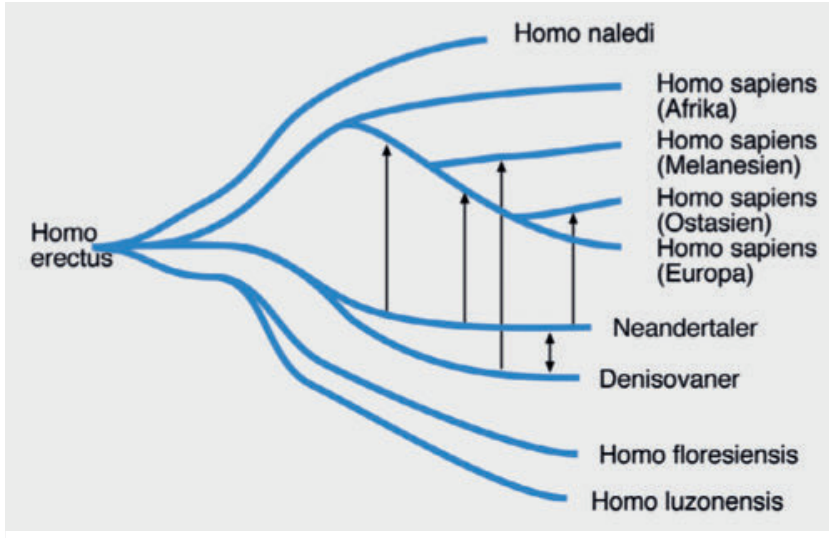

- Abb. 6 Stammbaum von, und Gen-Austausch zwischen unseren Vorfahren (nach Daten aus [105] und ergänzt).

cherte Erbgut. Dieses wird als nukleäre DNA bezeichnet (lateinisch: nucleus - Kern) und besteht aus etwa 3,2 Milliarden Basenpaaren (das ist etwa 200 000-mal mehr als die mtDNA), die 20000 Proteine kodieren und vor allem auch regulieren. Die mtDNA ist daher leichter zu finden und zu untersuchen als die nukleäre DNA - auch in Fossilen.

Eine Eizelle ist grundsätzlich viel größer als eine Samenzelle ${ }^{6}$. Eine menschliche Eizelle enthält etwa 200000-300 000 Mitochondrien, eine Samenzelle dagegen nur etwa 50-100. Diese werden gleich zu Beginn der Teilung der Eizelle nach der Befruchtung in 2 und dann in 4 Tochterzellen abgebaut, sodass die mütterlichen Mitochondrien an die Nachkommen weitergegeben werden. Geschwister haben daher die gleiche mtDNA, weswegen auch Krankheiten, die auf mutierten mitochondrialen Genen beruhen, nur über die Mutter an alle Kinder vererbt werden. In unserem Zusammenhang ist von Bedeutung, dass man aus diesem Grund mit mtDNA weibliche Abstammungslinien nachverfolgen kann. So wurde bereits im Jahr 1987 ein Stammbaum des Menschen aus der mtDNA (durch Bestimmung sogenannter Restriktionslängenpolymorphismen ${ }^{7}$ ) von 147 Menschen aus aller Welt [18] und 7 unterschiedliche „Äste“ sowie der Ort (Afrika) und die etwaige Zeit (vor 175000 Jahren) der „mitochondrialen Eva“ identifiziert, d. h. der Mutter aller heute lebenden Frauen. Später wurde das Alter der „mitochondrialen Eva“

6 Dies ist übrigens kein empirischer Befund, sondern definitionsgemäß der Fall. Wer glaubt, das Geschlecht eines Individuums werde durch das Geschlechtschromosom (beim Menschen X oder Y) festgelegt, der irrt. Welches von 2 sich geschlechtlich fortpflanzenden Lebewesen das Männchen und welches das Weibchen ist, ist vielmehr durch die Größe der jeweils beigetragenen Geschlechtszellen (Gameten) bestimmt: Die größere von beiden wird „Eizelle“ und das diese beitragende Individuum „weiblich“ genannt, die kleinere von beiden wird „Samenzelle“ und der Produzent „männlich“ genannt. „Weiblich“ ist damit - ganz allgemein bei Pflanzen und Tieren - per Definition das Individuum, das den höheren Beitrag (Verhaltens- und Evolutionsbiologen sprechen auch von „Investment“) leistet.

7 Der Restriktionslängenpolymorphismus, auch Restriktionsfragmentlängenpolymorphismus genannt, ist auch unter der Bezeichnung „genetischer Fingerabdruck" bekannt und war die erste kostengünstige Methode zum Vergleich der Verwandtschaft zweier Proben genetischen Materials. Die Methode wurde mittlerweile durch genauere neuere Methoden weitgehend ersetzt. 
genauer auf 99 000-148 000 Jahre bestimmt [67]. 13 Jahre später wurde die mtDNA dann bei 53 Personen sequenziert und die Ergebnisse verfeinert und bestätigt [42]. Der kürzlich verstorbene britische Genetiker Bryan Sykes machte weltweit Schlagzeilen mit seinem im Jahr 2001 erschienen Buch Die Sieben Töchter von Eva, in welchem er die Ausbreitung der mtDNA in Europa nachzeichnete $[74,94]$. Er war bereits Jahre zuvor an der genetischen Analyse der 1991 in den Ötztaler Alpen gefundenen, etwa 5300 Jahre alten Gletschermumie, genannt Ötzi, beteiligt [35] und konnte mittels weiterer Analysen eine in Großbritannien lebende Verwandte des Eismanns ausfindig machen [94].

Was bei den weiblichen Abstammungslinien die mtDNA ist, ist bei männlichen Abstammungslinien die DNA des Y-Chromosoms, das bekanntermaßen vom Vater auf die Söhne vererbt wird. Verfolgt man alle Y-Chromosomen nach Art eines Stammbaums genetisch auf das „Ur-Y-Chromosom“ zurück, erhält man den „genetischen Adam“ der heute lebenden Menschen. So wurden nochmals 13 Jahre später die gesamten Genome von 69 Männern aus 9 unterschiedlichen Populationen sequenziert [67] und die Zeit zurück bis zum jüngsten gemeinsamen Vorfahren des heutigen Y-Chromosoms und damit aller heutigen Männer mit 120000-156000 Jahren ermittelt. Dieses Alter des „genetischen Adam“ entspricht damit dem genannten Alter der „genetischen Eva“. Nach einer im Februar 2021 publizierten Studie stammt das Y-Chromosom aller heute in Europa und Asien lebenden Männer (ausschließlich der aus Afrika ausgewanderten Migranten) von einem gemeinsamen Vorfahren ab, der in Ost- oder Südostasien vor 50 000-55000 Jahren gelebt hat [34]. Setzen wir nun die Diskussion unserer Vorfahren chronologisch weiter fort.

\section{Der Neandertaler}

Ein gutes halbes Jahrhundert vor dem beschriebenen Unterkiefer - im Jahr 1856 - wurden im nordrhein-westfälischen Neandertal von Arbeitern in einem Steinbruch Schädelknochen gefunden, die später zusammen mit vielen weiteren Funden aus ganz Europa der Art Homo neandertalensis zugeordnet wurden. Der Körper des Neandertalers war mit $160 \mathrm{~cm}$ etwas kleiner als der von Homo sapiens, das Körpergewicht war jedoch ähnlich, sodass der Neandertaler gedrungener wirkte. Früher hätte man „plump“ gesagt und der bekannte Mediziner und Zoologe Ernst Haeckel nannte den Neandertaler im Jahr 1895 noch Homo stupidus [121, S. 601]. Dieses Bild vom Neandertaler hat sich mittlerweile aufgrund archäologischer und paläogenetischer Daten völlig gewandelt. Vieles deutet darauf hin, dass Neandertaler in ähnlicher Weise wie wir zum Denken fähig war und Sprache besaß. Möglicherweise haben die Neandertaler dem modernen Menschen sogar neue Fähigkeiten beigebracht, denn die beiden Spezies lebten über Jahrzehntausende nebeneinander, trafen aufeinander und paarten sich auch, wie genetische Analysen zeigten [32, 68]. Man hat mittlerweile durch den Vergleich genetischer Daten aus verschiedenen Fundstellen damit begonnen, eine Art Stammbaum des Neandertalers zu rekonstruieren [12].

Die Neandertaler lebten als Jäger und Sammler in Familiengruppen aus 5-10 Individuen. Sie jagten Groß- und Kleinsäugetiere. Sie verwendeten hierzu Holzspeere, später mit Steinspitzen. Tierfelle dienten als Wärmeisolation gegen Kälte, weswegen sich der
Neandertaler weiter nördlich ausbreiten konnte. Je nach Umgebung ernährte sich der Neandertaler vielfältig von Beeren, Früchten, Pflanzensamen, Hülsenfrüchten, Knollen, Muscheln, Wurzeln, Fisch und Fleisch. Sie würzten ihr Essen mit Wildkräutern, kochten schon vor 32000 Jahren Brei (also lange bevor die Töpferei und der Ackerbau erfunden wurden $)^{8}$ und kümmerten sich um ihre Kranken und Verletzten, auch wenn diese nicht mehr fähig waren, für sich selbst zu sorgen. Das lässt sich aus Skelettfunden von Individuen ableiten, die trotz schwerer Verletzungen noch lange weiter gelebt haben müssen, wie man an Verwachsungen der Knochen sehen kann. Auch kannten die Neandertaler die Wirkungen von Weidenrinde (enthält das Schmerzmittel Salicylat) und Hefepilzen (enthalten das Antibiotikum Penicillin). Sie bestatteten ihre Toten, trugen Schmuck und produzierten Malereien und Kunstgegenstände. Das Gehirnvolumen der Neandertaler lag mit 1200-1750 cm³ etwas über dem des heutigen Menschen. Die letzten fossilen Spuren des Neandertalers enden vor etwa 32000 Jahren [115]. Die jüngsten Funde am Südwestzipfel Europas in der Gorham Höhle auf Gibraltar sind etwa 24000 Jahre alt [25].

Bereits im Jahr 1997 wurde die allererste Neandertaler-DNA-Sequenz - ein kleiner Teil des mitochondrialen Genoms - von genau dem Individuum bestimmt, das 1856 im Neandertal, gefunden worden war [51]. Seitdem haben Verbesserungen der molekularen Techniken es ermöglicht, qualitativ hochwertige Sequenzen des autosomalen Genoms mehrerer Neandertaler zu bestimmen, was unter anderem - allein durch die Untersuchungen der DNA - zur Entdeckung einer völlig neuen Gruppe ausgestorbener Menschen, der Denisovaner, geführt hat [71].

Im Jahr 2014 fanden 2 Untersuchungen unabhängig voneinander heraus, dass insgesamt etwa $20 \%$ des Neandertaler-Genoms in heutigen Menschen zu finden ist [81, 102]. Umgekehrt machen die Gene des Neandertalers beim überwiegenden Teil der heute lebenden Menschen etwa 1-4\% des Genoms aus. Unsere direkten Vorfahren (Homo Sapiens) müssen sich also - etwa vor 37000 86000 Jahren - mit Neandertalern gepaart haben [80], was nach heutigem Wissen mehrfach bzw. vielfach geschehen sein muss. Dies wird auch durch den Fund eines modernen Menschen (Homo sapiens) untermauert, der vor etwa 37 000-42 000 Jahren im heutigen Rumänien (Peştera cu Oase) gelebt hat und dessen Erbgut zeigt, dass 4-6 Generationen vor ihm ein Neandertaler zu seinen Vorfahren gehört hatte [27]. Im Gegensatz zu diesem Fund und einem weiteren dieser Art aus Sibirien [26], deren Gene in heute lebenden Menschen nicht mehr nachweisbar sind, wurde erst kürzlich der Fund dreier moderner Menschen (Homo sapiens) publiziert, die vor 45 930-42 580 Jahren im heutigen Bulgarien (Bacho Kiro Höhle) gelebt hatten und deren Erbgut zeigt, dass alle 3 Individuen wenige Generationen zuvor einen Neandertaler als Vorfahren hatten, und dass diese Gene noch unter den heute in Ostasien sowie Nord- und Südamerika lebenden Menschen zu finden sind [33].

Dieses „Hineingehen“ von Genen des Neandertalers in die Linie des Homo sapiens - man spricht von Introgression - lässt sich mitt-

8 Wahrscheinlich kochten die Neandertaler entweder in Erdlöchern mit heißen Steinen oder in einem Hautsack oder einer Birkenrindenschale. Wasser kocht bei einer Temperatur, die unter dem Entzündungspunkt vieler brennbarer Materialien liegt, die als Behälter verwendet werden können. Daher kann man in brennbarer Rinde oder in brennbaren Häuten tatsächlich kochen. 
lerweile modellieren, indem man die Häufigkeiten unterschiedlicher Typen (Allele) von Genen, die durch Introgression erworben wurden, mit sogenannten Vermischungsgraphen (d. h. hypothetischer Stammbäume) vergleicht und durch statistische Verfahren (Varianz und Kovarianz in Allelfrequenzen zwischen Populationen an bestimmten Gen-Loci) den mit der höchsten Wahrscheinlichkeit bestimmt. So identifizierte man bereits Fälle, in denen Neandertaler-Introgressionsallele unmittelbar vorteilhaft und daher schnell vorherrschend waren, und andere Fälle, in denen sie für einige Zeit auf niedriger Frequenz persistierten. Für einige dieser Allele mit zunächst niedriger Frequenz wurde zudem gezeigt, dass die Selektion sie wahrscheinlich später unabhängig in geographisch getrennten Populationen begünstigte. Die Vermischung mit dem Neandertaler hat also zur Anpassung des modernen Menschen beigetragen [110]. Das bedeutet auch, dass Homo neandertalensis und Homo sapiens keine eigenständigen Arten sind und der Neandertaler nicht wirklich ausgestorben ist, sondern - zu $20 \%$ - in uns weiterlebt. Nicht zuletzt aus diesen Gründen war man bei der Entdeckung des Denisova-Menschen von Anfang an vorsichtiger und bezeichnete ihn nicht als neue Art, sondern ließ diese Frage offen. Svante Pääbo selbst hat kürzlich in einem Interview zur Fragen dieser Art wie folgt Stellung bezogen: „Ehrlich gesagt vermeide ich lieber diese Frage. Ich empfinde das als eine akademische, sterile Diskussion. Es gibt keine Artdefinition, die für alle Gruppen von Tieren oder Hominiden zutrifft" [43, S. 34].

\section{Der Denisova-Mensch}

Der Denisova-Mensch wurde erst vor gut einem Jahrzehnt entdeckt, und zwar allein anhand seiner Erbinformation (DNA), zunächst anhand der mtDNA [50] und wenige Monate später anhand der nukleären DNA [71, 72]. Die Erbinformation war besonders gut erhalten, weil der kleine Knochenfund, aus dem die DNA extrahiert wurde, aus der eponymen Denisova-Höhle im kalten Sibirien stammt. Kälte konserviert! Bis zu $6 \%$ der Denisova-DNA stimmt mit der DNA von Menschen überein, die heute auf Papua-Neuguinea und den östlich davon liegenden, pazifischen Inselgruppen leben, die man zusammenfassend als Melanesien bezeichnet $[58,96]$. In geringerer Häufigkeit von 1-2\% findet man Denisova-DNA heute in ganz Ostund Südasien, dem vermutlichen recht großen damaligen Verbreitungsgebiet des Denisova-Menschen. Man muss daraus schließen, dass es vor Jahrzehntausenden auch zur Paarung von Denisovanern und Mitgliedern unserer Spezies, Homo sapiens, kam und Nachkommen gezeugt wurden [71, 72]. Mittlerweile weiß man, dass dies mindestens 2-mal geschehen sein muss [14], wahrscheinlich jedoch insgesamt öfter - ähnlich wie bei Neandertaler und Homo sapiens - vorgekommen sein dürfte. Mittlerweile wurde sogar in der Denisova-Höhle selbst das Bruchstück eines Knochens eines etwa 13-jährigen Mädchens gefunden, das vor etwa 90000 Jahren gelebt hat und genetisch von einem Denisova-Vater und einer Neandertal-Mutter abstammte [89]. Diese Entdeckung - eine kleine menschheitsgeschichtliche Sensation! - machte endgültig klar, dass solche Paarungen keineswegs selten gewesen sein können, was übrigens die Vorsicht der Wissenschaftler bei der Verwendung des Artbegriffs durchaus berechtigt erscheinen lässt.

Die Gene des Denisova-Menschen haben nach neuen Untersuchungen bei heute lebenden Menschen eine Bedeutung für das
Leben in großen Höhen (Tibet [122]) und die Immunabwehr [14, 101]. Erst im Jahr 2019 ergab die Analyse von Proteinen in einem Kieferknochen, der in einer Höhle des tibetischen Plateaus in 3280 m Höhe gefunden wurde, dass es sich (1) um einen Denisova-Menschen gehandelt hat und dass (2) die genetische Anpassung an das Leben in großen Höhen, wie man sie bei den Bewohnern von Tibet heute findet, bereits beim Denisova-Menschen vorlag. Daraus muss man folgern, dass (3) diese Anpassung von den Denisovanern durch Paarung auf Homo sapiens überging, der sich erst viel später (vor 30 000-40 000 Jahren) dort ansiedelte [19, 105]. Da im Altai-Gebirge auch Knochen eines Neandertalers [68] gefunden wurden, ist es möglich, dass sich dort Neandertaler und Denisovaner über längere Zeiträume bzw. immer wieder einmal getroffen haben.

Ende des Jahres 2020 erschien eine sehr interessante genetische Studie zur mitochondrialen DNA und zum Y-Chromosom der Neandertaler, Denisovaner (von denen man bislang vor allem Frauen und daher kein Y-Chromosom gefunden hatte) und des heutigen Menschen [66]. Die Daten lassen vermuten, dass ein Homo-sapiens-Mann vor mehr als 100000 , aber weniger als 370000 Jahren mit einer Neandertal-Frau einen Sohn gezeugt haben muss, der (aus Gründen, über die man noch diskutiert [31]) besser angepasst war und dessen Nachkommen das Y-Chromosom des $\mathrm{Ne}$ andertalers verdrängte. Denn das Y-Chromosom der mittlerweile untersuchten jüngeren Neandertaler aus den Regionen des heutigen Belgien, Spanien und Russland von vor 38000-53000 Jahren war vom Y-Chromosom des Denisova-Menschen deutlich stärker unterschieden als unserem Y-Chromosom (Homo sapiens), obwohl es sich beim übrigen Genom genau anders herum verhält: Da stehen Neandertaler und Denisovaner nahe beieinander und beide sind weiter entfernt von Homo sapiens. Und damit noch nicht genug: Analysen der mtDNA legen nahe, dass eine Homo-sapiens-Frau vor mehr als 220000 Jahren mit einem Neandertal-Mann Nachkommen gezeugt haben muss, die sich ebenfalls durchsetzten, sodass die späteren Neandertaler auch ihre mitochondriale DNA von Homo sapiens erhielten. Interessanterweise wurden die jeweils beteiligten Vertreter von Homo sapiens nicht zu unseren Vorfahren, sondern gehörten zu einer schon sehr früh aus Afrika ausgewanderten und dann ausgestorbenen Population. Die beschriebenen 1-4\% Neandertaler-DNA in heute nicht in Afrika lebenden Menschen stammt aus deutlich späteren Vermischungen vor 50 000-70 000 Jahren. Wenn diese Arbeit von Petr und Mitarbeitern [66] eines nochmals sehr deutlich zeigt, dann ist es die Tatsache, dass die Menschheitsgeschichte voller Mischungen zwischen unseren zunächst getrennt entstandenen Vorfahren ist. Nach einer im Februar 2021 publizierten Studie stammt das Y-Chromosom aller heute außerhalb von Afrika lebenden Männer entgegen früheren Vermutungen (Europa) aus Südostasien und driftete dann gegen Westen [34]. Sofern man deutlich jüngere Ereignisse betrachtet [125], könnte es auch brutaler zugegangen sein als nur durch genetic drifting allein.

\section{Homo floresiensis, Homo luzonensis und Homo naledi}

Bei Homo floresiensis und Homo naledi handelt es sich um regionale Nachfahren des Homo erectus, die ausgestorben sind und nicht zu unseren direkten Vorfahren gehören [84]. Beide haben ein relativ 
kleines Gehirn, was entweder auf die Abstammung von einem relativ frühen Homo erectus oder auf Rückbildungsprozesse, die unter bestimmten Bedingungen der Isolation einer Gemeinschaft auftreten können, oder auf beides, zurückgeführt wird. Der Homo floresiensis wurde im Jahr 2004 erstmals beschrieben [13] und stellte eine Sensation dar, weil die Funde zunächst als „nur“ 18000 Jahre alt datiert worden waren. Eine neuere Datierung ergab jedoch, dass er bis vor etwa 60000 Jahren [93] auf der indonesischen Insel Flores lebte, die namensgebend war. Er war etwa einen Meter groß und wurde nach den kleinen Menschen in Tolkiens „Herr der Ringe“ auch oft als Hobbit bezeichnet. Das Innenvolumen eines beispielhaften Schädels betrug $417 \mathrm{~cm}^{3}$.

Im Jahr 2010 wurden Vormenschen auf Flores gefunden, deren Alter recht genau auf eine Million Jahre datiert werden konnte [15]. Wegen der Form des Schädels wurde Homo floresiensis der Gattung Homo zugeordnet und gilt als eine Verkleinerung (wie sie auf Inseln evolutionär entstehen können) von Homo erectus. Sein langer und zugleich eigenartig proportionierter Fuß könnte auch auf die Abstammung von einem früheren Vertreter der Gattung Homo (Homo habilis?) hinweisen [44], sein Gehirn war jedoch trotz seiner Kleinheit ähnlich wie das von Homo sapiens strukturiert [23]. Er besaß einfachste Steinwerkzeuge und jagte zwergwüchsige Verwandte des Elefanten (Stegodon), wie Schnittspuren an deren Knochen zeigen, die in den gleichen Schichten wie Homo floresiensis gefunden wurden [79].

Erst im April 2019 wurde eine weitere Art des Menschen beschrieben, die vor 67000 Jahren auf der indonesischen Insel Luzon gelebt hat, Homo luzonensis [21]. Nur 7 Zähne, 2 Finger- und 2 Zehenknochen, ein Mittelfußknochen sowie 2 Stücke eines kindlichen Oberschenkelknochens von 3 Individuen (2 Erwachsene und ein Kind) liegen vor. Die Zähne sind verglichen mit denen der heutigen Menschen klein. Die Finger- und Zehenknochen sind gebogen, ähnlich wie beim Australopithecus und verweisen auf das Leben auf Bäumen. Weil die Form der Funde zu keinem unserer bereits bekannten Vorfahren und auch nicht zum jetzigen Menschen passte, musste man von einer neuen Art ausgehen. Die Inseln Luzon und Flores haben eine vergleichbare geologische Geschichte. Als der Meeresspiegel während der Eiszeiten mehrere Male um bis zu 120 Meter niedriger lag als heute, waren beide Inseln zwar nicht mit dem südostasiatischen Festland verbunden, könnten aber mit einem Floß erreichbar gewesen sein. Steigende Meeresspiegel sorgten dann dafür, dass die dort lebenden Menschen - Homo floresiensis und Homo luzonensis - jeweils isoliert vom Rest der Welt blieben und sich wahrscheinlich in ihrer Größe zurück entwickelt haben.

Homo naledi ist eine ausgestorbene Art der Gattung Homo. Die Art wurde im Jahr 2015 anhand von Fossilien aus der Rising-Star-Höhle (Südafrika) von einer Arbeitsgruppe um Lee Berger in der Fachliteratur erstmals beschrieben [7, 8]. Aufgrund seines Aussehens und geringen Schädelvolumens (610 cm³; [36]) wurde der Fund zunächst als sehr alt, bis zu 2 Millionen Jahre, angesehen. Eine neue Datierung mit 3 Methoden konnte das Alter des Fundes jedoch auf zwischen mindestens 236000 und 335000 Jahren feststellen, also deutlich jünger [22]. Dies ist im Grunde noch spannender, denn es zeigt, dass zu einer Zeit, als in Afrika schon seit langem deutlich weiterentwickelte Menschen lebten, zugleich noch einfachere Typen von Menschen gelebt haben müssen [30].

\section{Homo sapiens}

Nachdem das menschliche Genom - bestehend aus etwa 3,2 Milliarden Basenpaaren - mit einem riesigen Aufwand ${ }^{9}$ im Rahmen des Human Genome Projekt im Jahr 2003 erst einmal entschlüsselt worden war, taten sich weitere ganz neue und vielfältige Möglichkeiten auf, die Menschheitsgeschichte - von prähistorischer Zeit bis hinein in die jüngste Geschichte - genauer zu untersuchen. Denn durch genetische Analysen vieler heute lebender Menschen aus unterschiedlichen Regionen der Welt wurde es möglich, zusammen mit der Analyse von DNA aus fossilen oder historischen Funden, den Stammbaum und Verwandtschaftsverhältnisse der heute weltweit lebenden Menschen aufzuklären.

Über den vorderen Orient (Gebiete des fruchtbaren Halbmonds) kamen vor etwa 50 000-60000 Jahren dann die ersten Vertreter des dort vor etwa 200000 Jahren entstandenen Homo sapiens aus Afrika nach Europa, wie Funde aus Bulgarien [33], Rumänien, Tschechien und Sibirien zeigen. Bereits zuvor fand man in Afrika die älteste bekannte Grabstätte von Homo sapiens, deren Alter auf 78300 Jahre [117] datiert wurde. Ebenfalls in Afrika fand man die älteste Schmucksteinsammlung von doppelbrechenden Calcit-Kristallen (Alter 105000 Jahre; [107]) und älteste Schmuckstücke aus aufgefädelten, durchbohrten (Meeresschnecken-) Schalen (75000 Jahre; [2, 38]. Abgerundete und mit einem Loch versehene Straußenei-Schalen dienten, als Kette getragen, schon vor mehr als 30000 Jahren bei den im heutigen Südafrika und Namibia lebenden San Buschleuten als eine Art Tausch- oder Zahlungsmittel in größeren sozialen Netzwerken, die dadurch stabilisiert werden [90]. Da die Jäger und Sammler-Kultur der San bis heute besteht, werden diese Ketten noch immer gefertigt und stellen damit wahrscheinlich die älteste bis heute über 33 Jahrtausende existierende kulturelle Tradition zu am Körper getragenem Schmuck dar (\ Abb. 7).

Zu den beeindruckendsten Zeugnissen des Homo sapiens der Vorzeit zählen zweifellos die von unseren Vorfahren geschaffenen Kunstwerke. Die ältesten von ihnen stammen nicht aus Europa, sondern aus Indonesien und wurden in den letzten Jahren in Höhlen auf der Insel Sulawesi entdeckt. Das mindestens 45500 Jahre alte, früheste gegenständliche Gemälde Welt zeigt ein Pustelschwein sowie (als „Negativ-Abdruck“) 2 menschliche Hände [15]. Kurz zuvor waren von derselben Arbeitsgruppe bereits Höhlenmalereien mit mindestens 43900 Jahre alten Tierabbildungen in demselben Karstgebiet im Südwesten von Sulawesi publiziert worden [126], die Jagdszenen und sogar Mensch-Tier-Hybridwesen - sogenannte Therianthropen - zeigen, deren älteste Darstellungen man zuvor in der Nähe von Ulm (Löwenmensch) lokalisiert und mit einem Alter

$9 \quad$ Nicht nur das weltweit größte Gesundheits-Forschungszentrum, das US-amerikanische National Institute of Health (NIH) arbeitete seit 1990 daran, sondern etwa 1000 Wissenschaftler weltweit sowie die eigens von dem US-amerikanische Biochemiker und Unternehmer Craig Venter 1998 dafür gegründete, private Firma Celera. Kostete die erste Analyse noch etwa 2,7 Milliarden US-Dollar [61], so kostet die Analyse eines menschlichen Genoms dank enormer methodischer Fortschritte mittlerweile weniger als 1000 US\$ und wird bald zu den „Routinelaboruntersuchungen“ in der Medizin zählen. Wenn Gesundheitsinformationen erst einmal flächendeckend und zuverlässig (und gut verschlüsselt) digital vorliegen, wird es irgendwann sehr bald möglich, das Genom eines Menschen im Rahmen von dessen Geburt zu bestimmen, um darauf aufbauend direkt danach mit der personalisierten Medizin (z. B. der Prophylaxe wahrscheinlich auftretender Erkrankungen) zu beginnen. 


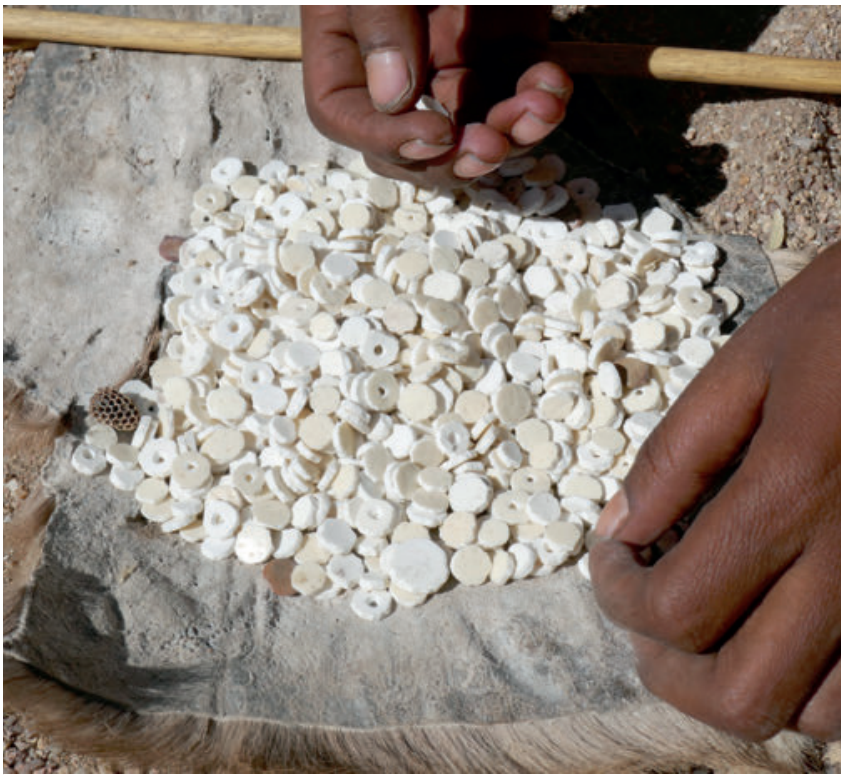

- Abb. 7 Das Einzige, was sich in Jahrzehntausenden bei der Herstellung von Ketten aus den Eierschalen von Straußeneiern geändert hat, ist die Verwendung eines Stahlbohrers, der nicht so oft abbricht wie der früher verwendete Steinbohrer. Die San Buschleute leben ansonsten noch heute wie in der Steinzeit (Foto: @ Autor).

von etwa 40000 Jahren datiert hatte. Nach der letzten Eiszeit (vor etwa 12000 Jahren) brachten unsere Vorfahren dann Gesellschaften, Hochkulturen und schließlich Schrift und Wissenschaft hervor.

In seinem 2018 erschienenen Buch Wer wir sind und wie wir dahin kamen [73] fasst der Genetiker David Reich, seit 2003 Professor an der Harvard Medical School, die größten Entdeckungen im Bereich der humangenetischen Forschung zusammen. Dort hat es im vergangenen Jahrzehnt - man kann das ohne Übertreibung sagen - eine Revolution gegeben, was unser Verständnis der Verbreitung des Menschen in den letzten 60000 Jahren anbelangt. Reich diskutiert nicht nur die Herkunft der „modernen“ Europäer, sondern auch die Besiedelung von Asien und Indien sowie von Amerika. Es ist verblüffend, mit welchen raffinierten Methoden man heute Fragen beantworten kann, die man noch vor 10 Jahren nicht einmal im Traum zu stellen gewagt hätte. Dazu gehört auch die Folgende.

\section{Neandertaler und COVID-19?}

Bekanntermaßen variiert der Krankheitsverlauf von Menschen, die mit SARS-CoV-2 infiziert sind, erheblich: Einige merken gar nichts, viele haben eine Art Schnupfen und andere erkranken schwer an COVID-19, von denen einige versterben. Sehr bald wurden hohes Alter, männliches Geschlecht und verschiedene Vorerkrankungen als Risikofaktoren für einen ungünstigen Krankheitsverlauf beschrieben. Wissenschaftler machten sich daher bald nach Ausbruch der Pandemie auch auf die Suche nach genetischen Unterschieden zwischen Menschen mit leichtem und schwerem Krankheitsverlauf, und bereits im Mai 2020 wurde hierzu eine internationale Initiative gegründet (COVID-19 Host Genetics Initiative 2020). Im Sommer 2020 wurde im New England Journal of Medicine (NEJM) die erste genomweite Assoziationsanalyse (GWAS) zu genetischen
Risikofaktoren von einer weiteren internationalen Arbeitsgruppe publiziert [86]. Dazu wurden schwer an COVID-19 erkrankte Patienten - definiert als Patienten mit respiratorischem Versagen - in jeweils 7 Krankenhäusern sowohl im italienischen als auch im spanischen Zentrum für die SARS-CoV-2-Pandemie in Europa genetisch untersucht. Insgesamt wurden 835 Patienten und 1255 Kontrollteilnehmer aus Italien, sowie 775 Patienten und 950 Kontrollteilnehmer aus Spanien in die endgültige Analyse von 8582968 Einzel-Nukleotid-Polymorphismen eingeschlossen. Tatsächlich wurde ein Gen-Ort mit 6 Genen auf Chromosom 3 mit signifikanter Assoziation zum Versagen der Atmung gefunden. Eine weitere Region auf Chromosom 9 wurde ebenfalls gefunden. Die Gene dort bestimmen die AB0-Blutgruppe, von der bereits bekannt war, dass sie einen Einfluss auf den Krankheitsverlauf hat. Mittlerweile liegt eine weltweite Metaanalyse von 46 Studien aus 19 Ländern mit 49562 COVID-19 Patienten und 2 Millionen Kontrollen vor, die 15 signifikante Gen-Orte (Loci) beschreibt, die mit SARS-CoV-2-Infektion oder schwerem COVID-19-Verlauf assoziiert sind [97, 98].

Es konnte nicht ausbleiben, dass man sich Gedanken über die Funktion, aber auch über Verteilung bzw. Verbreitung dieser Gene auf der Welt und sogar deren Herkunft machte. In einem ersten Anlauf fanden Wissenschaftler des Max-Planck-Instituts für evolutionäre Anthropologie in Leipzig, dass der Risikofaktor auf dem Gen-Ort des 3. Chromosoms nahezu identisch ist mit dem entsprechenden Gen-Ort eines 50000 Jahre alten Neandertalers aus Südeuropa. Weitere Analysen konnten zeigen, dass diese Variante auf die Vorfahren des modernen Menschen vor etwa 60000 Jahren übergegangen ist, d. h. durch Paarung von Homo sapiens und Neandertaler in das Genom von Homo sapiens gelangte [112, 123, 124].

Überraschend war jedoch, dass die Verteilung dieser genetischen Variante in den häufigsten Populationen der Welt nicht vollständig mit der bekannten Verteilung der Neandertaler-Gene korrelierte. Während bei Afrikanern die Risiko-Variante vorhersehbar fehlte, da sie bekanntermaßen keine bzw. fast keine Neandertaler-Gene in sich tragen, steht die dramatische Anreicherung bei Menschen aus Südasien und deren nahezu vollständiges Fehlen in Ostasien im Widerspruch zu veröffentlichten Schätzungen des Neandertaler-Beitrags zu diesen Populationen. Dies deutet darauf hin, dass dieses Risiko-Gen in verschiedenen Populationen einem starken Selektionsdruck in entgegengesetzter Richtung unterlegen haben könnte. Die Gründe dafür werden derzeit noch diskutiert [110-113, 59, 60]. Nachdem erst einmal eine Variante der Suszeptibilität gegenüber COVID-19 identifiziert worden war, erlaubten neuere, größere genetische Assoziationsstudien zu den Risikofaktoren dieser Krankheit das weitere, noch genaueres Suchen. Anhand von Daten des Genetics of Mortality in Critical Care (GenOMICC) Konsortiums konnten Zeberg und Pääbo im Januar 2021 zeigen, dass eine Gensequenz in einer Region auf dem menschlichen Chromosom 12 ebenfalls fast identisch ist mit derjenigen, die bei einem etwa 50000 Jahre alten Neandertaler aus Kroatien gefunden wurde. Auch war sie fast identisch mit weiteren 2 Neandertalern aus Südsibirien, von denen einer etwa 70000 und der andere etwa 120000 Jahre alt ist [114]. Diese Gensequenz kodiert Proteine, die ihrerseits Enzyme aktivieren, die bei Infektionen mit dem Virus SARS-CoV-2 vor schweren Verläufen von COVID-19 mit einer Effektstärke von etwa 22 \% schützen. Diese Neandertaler-Gensequenz 
unterscheidet sich von der genannten Risiko-Gensequenz nicht nur dadurch, dass sie einen geringeren Effekt hat, sondern insbesondere dadurch, dass sie in allen Regionen der Welt außerhalb Afrikas in beträchtlicher Häufigkeit vorkommt. Aus ihren Daten leiten die Autoren ab, dass die Häufigkeit dieser schützenden Neandertaler-Gensequenz im Genom von Homo sapiens zugenommen hat, und zwar vor allem im westlichen Eurasien (also dem Gebiet, in dem die Neandertaler zuvor lebten) vor 20000 bis vor 10000 Jahren (als es also schon keine Neandertaler mehr gab) und danach sogar noch einmal während der letzten 1000 Jahre, ebenfalls in Westeuropa.

Eine kürzlich publizierte Studie untersuchte die Verteilung des genetischen COVID-19-Risikos auf Chromosom 3 auf der Arabischen Halbinsel und diskutierte dies im Zusammenhang mit der Verteilung von Genen des Neandertalers in der lokalen Bevölkerung [60]. Proben der häufigsten indigenen Stämme wurden genotypisiert [59], und die Häufigkeit des Risiko-Allels mit 8,6\% bestimmt. Da wegen der frühen Abspaltung der Araber von den weiter nach Norden wandernden Vertretern von Homo sapiens auch der Mischungsgrad von deren Nachfahren mit dem Neandertaler vergleichsweise geringer ist (wie erwähnt, nur 2,6\%, im Gegensatz zu ca. $4 \%$ in Westeuropa), passen diese Daten zunächst nicht zusammen, könnten aber durch eine positive Genselektion erklärt werden. Es könnten aber auch ganz andere, noch unbekannte Eigenschaften bzw. Auswirkungen dieser Gene zu entsprechenden Selektionsprozessen geführt haben.

\section{Schlussbemerkung}

Dachte man noch vor 20 Jahren, wir wären seit langer Zeit als einzige Art in der Gattung Homo übrig geblieben, weil wir den anderen deutlich überlegen waren, so hat sich dieses Bild grundlegend gewandelt: Noch bis vor wenigen Jahrzehntausenden lebten wir gleichzeitig mit anderen Varianten des Menschen und hatten mit einigen von ihnen - den Neandertalern und den Denisovanern (und vielleicht in Afrika noch mit mindestens einem weiteren, bislang noch nicht entdeckten Vorfahren, worauf genetische Analysen hindeuten) - gemeinsame Nachkommen. Svante Pääbo [63, S. 313], einer der für diese Entdeckungen wesentlichen Wissenschaftler, drückt dies wie folgt aus: „Unsere Vorfahren waren Teil eines Netzwerks von mittlerweile ausgestorbenen Gesellschaften, die durch gelegentlichen oder zuweilen vielleicht auch andauernden Gen-Fluss miteinander verbunden waren “. ${ }^{10}$ Die Geschichte unserer Vorfahren ist alles andere als eine lineare Entwicklung mit uns Heutigen am Ende. Vielmehr ist es ein Geflecht von Gruppen, die sich aufteilten, an unterschiedliche Lebensbedingungen anpassten und wieder aufeinandertrafen, wobei sich ihr Erbgut mischte. Nebenbei bemerkt: Homo erectus war mit einer überdauerten Zeitspanne von knapp 2 Millionen Jahren bislang der erfolgreichste Vertreter der Gattung Mensch. Uns hingegen gibt es erst etwa 200000 Jahre. Den Gedanken, dass wir - die jetzigen Menschen - am erfolgreichsten sind, sollten wir daher für die nächsten 1,8 Millionen Jahre begraben.

10 „Our ancestors were part of a web of now-extinct populations linked by limited, but intermittent or sometimes perhaps even persistent, gene flow".
Die genetische Durchmischung erleichterte unseren Vorfahren die Anpassung an wechselnde Lebensbedingungen, indem sie Allele (also Typen bestimmter Gene) bereitstellt, die in einer neuen Umgebung sofort adaptiv sein können. Zudem bewirken sie genetische Vielfalt und damit ein langfristiges Reservoir an Möglichkeiten für zukünftige Anpassungen. Eine wachsende Zahl von Fällen solcher „adaptiver Introgression“ wurde nicht nur bei unseren Vorfahren, sondern quer durch die gesamte Evolution gefunden. Die Zeitpunkte von Vermischung und Selektion sind jedoch meist völlig unbekannt. Unsere Vorfahren und die mittlerweile zu ihnen vorliegenden Studien bilden hier die Ausnahme: (1) Der Vergleich von prähistorischen Funden mit genetischen Tests, (2) die Möglichkeit der genetischen Untersuchung von historischen Funden aus Gräbern und (3) die Methoden der Konstruktion von Stammbaum heute lebendender Menschen mittels mathematischer Analysen von deren Genom bieten ganz neue Möglichkeiten der Integration einer Vielfalt von Daten. So werden wir Zeitzeugen der räumlich über den gesamten Globus und zeitlich über die vergangenen Jahrhunderttausende bis hin in die Gegenwart (mit immer besserer Auflösung) stattfindenden Aufklärung unserer eigenen demografischen Geschichte des Wanderns und Zusammentreffens unterschiedlicher Populationen und Kulturen. Insgesamt stehen wir damit am Anfang und unsere Geschichte wird sich weiter ändern - vielleicht nicht mehr ganz so dramatisch wie in den letzten 20 Jahren.

\section{Literatur}

[1] Antón SC. All who wander are not lost. Science 2020; 368: 34-35

[2] Bar-Yosef Mayer DE, Bosch MD. Humans' Earliest Personal Ornaments: An Introduction. PaleoAnthropology 2019: 19-23

[3] Barras B. The tamed ape: were humans the first animal to be domesticated? New Scientist 21.2.2018 https://www.newscientist.com/ article/mg23731660-600-the-tamed-ape-were-humans-the-first-animal-to-be-domesticated/; abgerufen am 29.12.2020

[4] Bennett MR, Harris JWK, Richmond BG, et al. Early Hominin Foot Morphology Based on 1.5-Million-Year-Old Footprints from lleret, Kenya. Science 2009; 323: 1197-1201

[5] Bennett MR, Harris JWK, Richmond BG, et al. Early Hominin Foot Morphology Based on 1.5-Million-Year-Old Footprints from lleret, Kenya. Science 2009; 323: 1197-1201

[6] Berger LR. Predatory bird damage to the Taung type-skull of Australopithecus africanus Dart 1925. American Journal of Physical Anthropology 2006; 131: 166-168

[7] Berger LR, Hawks J, de Ruiter DJ, et al. Homo naledi, a new species of the genus Homo from the Dinaledi Chamber, South Africa. eLife 2015; ;4:e09560. doi:10.7554/eLife.09560

[8] Berger LR, Hawks J, Dirks PH, et al. Homo naledi and Pleistocene hominin evolution in subequatorial Africa. Elife 2017; 6: e24234

[9] Bergström A, Tyler-Smith C. Paleolithic networking. Science 2017; 358: 586-587

[10] Bergström A, Stringer C, Hajdinjak M, et al. Origins of modern human ancestry. Nature 2021; 590: 229-237

[11] Böhme M, Spassov N, Fuss J, et al. A new Miocene ape and locomotion in the ancestor of great apes and humans. Nature 2019; 575 : 489-493

[12] Bokelmann L, Hajdinjak M, Peyrégne S, et al. A genetic analysis of the Gibraltar Neanderthals. PNAS 2019; 116: 15610-15615 
[13] Brown P, Sutikna T, Morwood M, et al. A new small-bodied hominin from the Late Pleistocene of Flores, Indonesia. Nature 2004; 431: 1055-1061

[14] Browning SR, Browning BL, Zhou Y, et al. Analysis of Human Sequence Data Reveals Two Pulses of Archaic Denisovan Admixture. Cell 2018; 173: 53-61

[15] Brumm A, Jensen G, van den Bergh G, et al. Hominins on Flores, Indonesia, by one million years ago. Nature 2010; 464: 748-752

[16] Buck LT, Stringer, CB. Homo heidelbergensis (Quick guide). Current Biology 2014; 24: R214-R215

[17] Campbell RM, Vinas G, Henneberg M, et al. Visual Depictions of Our Evolutionary Past: A Broad Case Study Concerning the Need for Quantitative Methods of Soft Tissue Reconstruction and Art-Science Collaborations. Front Ecol Evol 2021; 9: 639048

[18] Cann RN, Stoneking M, Wilson AC. Mitochondrial DNA and human evolution. Nature 1987; 325: 31-36

[19] Chen F, Welker F, Shen CC, et al. A late Middle Pleistocene Denisovan mandible from the Tibetan Plateau. Nature 1999; 569: 409-412

[20] Dennell R. The world's oldest spears. Nature 1997; 3885: 767-768

[21] Détroit F, Mijares AS, Corny J, et al. A new species of Homo from the Late Pleistocene of the Philippines. Nature 2019; 568: 181-186

[22] Dirks PHGM, Roberts EM, Hilbert-Wolf H, et al. The age of Homo naledi and associated sediments in the Rising Star Cave, South Africa. eLife 2017; 6: e24231

[23] Falk D, Hildebolt C, Smith K, et al. The brain of LB1, Homo floresiensis. Science 2015; 308: 242-245

[24] Ferring R, Oms O, Agustí J, et al. Earliest human occupations at Dmanisi (Georgian Caucasus) dated to 1.85-1.78 Ma. PNAS 2011; 108: 10432-10436

[25] Finlayson C, Giles Pacheco F, et al. Late survival of Neanderthals at the southernmost extreme of Europe. Nature 2006; 443: 850-853

[26] Fu Q, Li H, Moorjani P, et al. Genome sequence of a 45,000-year-old modern human from western Siberia. Nature 2014; 514: 445-449

[27] Fu Q, Hajdinjak M, Moldovan OT, et al. An early modern human from Romania with a recent Neanderthal ancestor. Nature 2015; 524: 216-219

[28] Gibbons A. New human species discovered. Science 2015; 349: 1149-1150

[29] Gibbons A. The wanderers. Science 2016; 958-961

[30] Gibbons A. This mysterious human species lived alongside our ancestors, newly dated fossils suggest. Science 9.5.2017 https:// www.sciencemag.org/news/2017/05/mysterious-human-species-lived-alongside-our-ancestors-newly-dated-fossils-suggest; abgerufen am 16.5.2021

[31] Gibbons A. How neandertals lost their Y-chromosome. Science 24.9.2020 https://www.sciencemag.org/news/2020/09/how-neanderthals-lost-their-y-chromosome; abgerufen am 22.5.2021

[32] Green RE, Krause J, Briggs AW, et al. A draft sequence of the Neandertal genome. Science 2010; 328: 710-722

[33] Hajdinjak M, Mafessoni F, Skov L, et al. Initial Upper Palaeolithic humans in Europe had recent Neanderthal ancestry. Nature 2021; 592: $253-257$

[34] Hallast P, Agdzhoyan A, Balanovsky O, et al. A Southeast Asian origin for present-day non-African human $Y$ chromosomes. Hum Genet 2021; 140: 299-307

[35] Handt O, Richards M, Trommsdorff M, et al. Molecular genetic analyses of the Tyrolean Ice Man. Science 1994; 264: 1775-1778

[36] Hawks J, Elliott M, Schmid P, et al. New fossil remains of Homo naledi from the Lesedi Chamber, South Africa. eLife 2017; 6: e24232

[37] Henke W, Rothe H. Paläoanthropologie. Berlin; Springer, 1994
[38] Henshilwood C, d'Errico F, Vanhaeren M, et al. Middle Stone Age Shell Beads from South Africa. Science 2014; 304: 404

[39] Herries AIR, Martin JM, Leece AB, et al. Contemporaneity of Australopithecus, Paranthropus, and early Homo erectus in South Africa. Science 2020; 368: eaaw7293

[40] Higuchi R, Bowman B, Freiberger M, et al. DNA sequences from the quagga, an extinct member of the horse family. Nature 1984; 312 : 282-284

[41] Hublin JJ, Sirakov N, Aldeias V, et al. Initial Upper Palaeolithic Homo sapiens from Bacho Kiro Cave, Bulgaria. Nature 581: 299-302

[42] Ingman $\mathrm{M}$, Kaessmann $\mathrm{H}$, Pääbo $\mathrm{S}$, et al. Mitochondrial genome variation and the origin of modern humans. Nature 2020; 408: 708-713

[43] Jahn A. „Jeder besitzt Erbgut vom Neandertaler“ - Interview mit Svante Pääbo. Spektrum der Wissenschaft 2021; 5: 30-36

[44] Jungers WL, Harcourt-Smith WE, Wunderlich RE, et al. The foot of Homo floresiensis. Nature 2009; 459: 81-84

[45] Juric I, Aeschbacher S, Coop G. The Strength of Selection against Neanderthal Introgression. PLoS Genet 2016; 12: e1006340

[46] Keller A, Graefen A, Ball M, et al. New insights into the Tyrolean Iceman's origin and phenotype as inferred by whole-genome sequencing. Nat Commun 2012; 28: 698

[47] Kivell TL. Fossil ape hints at how walking on two feet evolved. Nature 2019; 575: 445-446

[48] Kolobova KA, Roberts RG, Chabai VP, et al. Archaeological evidence for two separate dispersals of Neanderthals into southern Siberia. PNAS 2020; 117: 2879-2885

[49] Krause J. Die Reise unserer Gene: Eine Geschichte über uns und unsere Vorfahren. Berlin: Propyläen Verlag, 2019

[50] Krause J, Fu Q, Good JM, et al. The complete mitochondrial DNA genome of an unknown hominin from southern Siberia. Nature 2010; 464: 894-897

[51] Krings M, Stone A, Schmitz RW, et al. Neandertal DNA sequences and the origin of modern humans. Cell 1997; 19-30

[52] Langergraber K, Pruefer K, Rowney C, et al. Generation times in wild chimpanzees and gorillas suggest earlier divergence times in great ape and human evolution. PNAS 2012; 109: 15716-15721

[53] Leakey MD, Hay RL. Pliocene footprints in the Laetolil Beds at Laetoli, northern Tanzania. Nature 1979; 278: 317-323

[54] Lordkipanidze D. Die ersten Europäer - die Fundstelle Dmanisi. In: Hessisches Landesmuseum Darmstadt (Hrsg): Expanding Worlds. Originale Urmenschen-Funde aus fünf Weltregionen. Darmstadt: Wissenschaftliche Buchgesellschaft, 2015

[55] Mafessoni F, Steffi Grote S, de Filippo C, et al. A high-coverage Neandertal genome from Chagyrskaya Cave. PNAS 2020; 117: 15132-15136

[56] Majkić A, Evans S, Stepanchuk V, et al. A decorated raven bone from the Zaskalnaya VI (Kolosovskaya) Neanderthal site, Crimea. PLoS ONE 2017; 12(3): e0173435

[57] Marzke MW. Precision grips, hand morphology, and tools. In: American Journal of Physical Anthropology 1997; 102: 91-110

[58] Meyer M, Kircher M, Gansauge MT, et al. A high-coverage genome sequence from an archaic Denisovan individual. Science 2012; 338: 222-226

[59] Mineta K, Goto K, Gojobori T, et al. Population structure of indigenous inhabitants of Arabia. PLoS Genet 2021; 17: e1009210

[60] Mineta K, Goto K, Gojobori T, et al. Indigenous Arabs have an intermediate frequency of a Neanderthal-derived COVID-19 risk haplotype compared with other world populations. Clin Genet 2021; 99: 484-485

[61] NIH. National Human Genome Research Institute: Human Genome Project FAQ, last updated: February 24, 2020 (https://www.genome. 
gov/human-genome-project/Completion-FAQ; abgerufen am 15.5.2021)

[62] Pääbo S. Molecular cloning of ancient Egyptian mummy DNA. Nature 1985; 314: 644-645

[63] Pääbo S. The diverse origins of the human gene pool. Nat Rev Genet 2015; 16: 313-314

[64] Pante MC, Njau JK, Hensley-Marschand B, et al. The carnivorous feeding behavior of early Homo at HWK EE, Bed II, Olduvai Gorge, Tanzania. J Hum Evol 2018; 120: 215-235

[65] Pauling L, Zuckerkandl E. Chemical paleogenetics: molecular restoration studies of extinct forms of life. Acta Chem Scand 1963; 17: 9-16

[66] Petr M, Hajdinjak M, Fu Q, Essel E, et al. The evolutionary history of Neanderthal and Denisovan Y chromosomes. Science 2020; 369: 1653-1656

[67] Poznik GD, Henn BM, Yee MC, et al. Sequencing Y chromosomes resolves discrepancy in time to common ancestor of males versus females. Science 2013; 34: 562-655

[68] Prüfer K, Racimo F, Patterson N, et al. The complete genome sequence of a Neanderthal from the Altai Mountains. Nature 2014; 505 : 43-49

[69] Prüfer K, de Filippo C, Grote S, et al. A high-coverage Neandertal genome from Vindija Cave in Croatia. Science 2017; 358: 655-658

[70] Reader SM, Hager Y, Laland KN.The evolution of primate general and cultural intelligence. Philosophical transactions of the Royal Society of London. Series B, Biological sciences 2011; 366: 1017-1027

[71] Reich D, Green RE, Kircher M, et al. Genetic history of an archaic hominin group from Denisova Cave in Siberia. Nature 2010; 468: 1053-1060

[72] Reich D, et al. Denisova admixture and the first modern human dispersals into Southeast Asia and Oceania. Am J Hum Genet 2011; 89: $516-528$

[73] Reich D. Who We Are and How We Got Here: Ancient DNA and the New Science of the Human Past. München: Pantheon, 2018

[74] Richards M, Côrte-Real H, Forster P, et al. Paleolithic and neolithic lineages in the European mitochondrial gene pool. Am J Hum Genet 1996; 59: 185-203

[75] Rizal Y, Westaway KE, Zaim Y, et al. Last appearance of Homo erectus at Ngandong, Java, 117,000-108,000 years ago. Nature 2020; 577: 381-385

[76] Rodriguez-Flores JL, Fakhro K, Agosto-Perez F, et al. Indigenous Arabs are descendants of the earliest split from ancient Eurasian populations. Genome Res 2016; 26: 151-162

[77] Ruff CB, Burgess ML, Ketcham RA, et al. Limb Bone Structural Proportions and Locomotor Behavior in A. L. 288-1 („Lucy“). PLoS ONE 2010; 11: e0166095

[78] Sandrock O, Schrenk F. Was Sie sich schon immer gefragt haben. In: Hessisches Landesmuseum Darmstadt (Hrsg): Expanding Worlds. Originale Urmenschen-Funde aus fünf Weltregionen. Darmstadt: Wissenschaftliche Buchgesellschaft, 2015

[79] Sandrock O, Schrenk F. Die Originale. In: Hessisches Landesmuseum Darmstadt (Hrsg): Expanding Worlds. Originale Urmenschen-Funde aus fünf Weltregionen. Darmstadt: Wissenschaftliche Buchgesellschaft, 2015

[80] Sankararaman S, Patterson N, Li H, et al. The date of interbreeding between Neandertals and modern humans. PLoS Genet 2012; 8: e1002947

[81] Sankararaman S, Mallick S, Dannemann M, et al. The genomic landscape of Neanderthal ancestry in present-day humans. Nature 2014; 507: 354-357

[82] Schmidt P, Blessing M, Rageot M, et al. Birch tar production does not prove Neanderthal behavioral complexity PNAS 2019; 116: 17707-17711
[83] Schmitz R. Der Neandertaler - eine Ikone der Urgeschichtsforschung. In: Hessisches Landesmuseum Darmstadt (Hrsg): Expanding Worlds. Originale Urmenschen-Funde aus fünf Weltregionen. Darmstadt: Wissenschaftliche Buchgesellschaft, 2015

[84] Schrenk F. Die Frühzeit des Menschen. Der Weg zu Homo sapiens. München: C. H. Beck, 2019

[85] Schrenk F, Sandrock O. Expanding Worlds. In: Hessisches Landesmuseum Darmstadt (Hrsg): Expanding Worlds. Originale Urmenschen-Funde aus fünf Weltregionen. Darmstadt: Wissenschaftliche Buchgesellschaft, 2015

[86] Severe Covid-19 GWAS Group; Ellinghaus D, Degenhardt F, et al. Genomewide Association Study of Severe Covid-19 with Respiratory Failure. N Engl ] Med 2020; 383: 1522-1534

[87] Sistiaga A, Husain F, Uribelarrea D, et al. Microbial biomarkers reveal a hydrothermally active landscape at Olduvai Gorge at the dawn of the Acheulean, 1.7 Ma. PNAS 2020; 117: 24720-24728

[88] Slon V, Hopfe C, Weiß CL, et al. Neandertal and Denisovan DNA from Pleistocene sediments. Science 2017; 356: 605-608

[89] Slon V, Mafessoni F, Vernot B, et al. The genome of the offspring of a Neanderthal mother and a Denisovan father. Nature 2018; 561 : $113-116$

[90] Stewart BA, Zhao Y, Mitchell P], et al. Ostrich eggshell bead strontium isotopes reveal persistent macroscale social networking across late Quaternary southern Africa. PNAS 2020; 117: 6453-6462

[91] Street SE, Navarrete AF, Reader SM, et al. Coevolution of cultural intelligence, extended life history, sociality, and brain size in primates. PNAS 2017; 114: 7908-7914

[92] Stringer CB, Trinkaus E, Roberts MB, et al. The Middle Pleistocene human tibia from Boxgrove. Journal of Human Evolution 1998; 34: 509-547

[93] Sutikna T, Tocheri M, Morwood M, et al. Revised stratigraphy and chronology for Homo floresiensis at Liang Bua in Indonesia. Nature 2016; 532: 366-369

[94] Sykes B. The Seven Daughters of Eve. New York: WW Norton, 2001

[95] Teixeira JC, Cooper A. Using hominin introgression to trace modern human dispersals. PNAS 2019; 116: 15327-15332

[96] Teixeira JC, Jacobs GS, Stringer C, et al. Widespread Denisovan ancestry in Island Southeast Asia but no evidence of substantial super-archaic hominin admixture. Nat Ecol Evol 2021; 5: 616-624

[97] The COVID-19 Host Genetics Initiative. The COVID-19 Host Genetics Initiative, a global initiative to elucidate the role of host genetic factors in susceptibility and severity of the SARS-CoV-2 virus pandemic. Eur J Hum Genet 2020; 28: 715-718

[98] The COVID-19 Host Genetics Initiative. Mapping the human genetic architecture of COVID-19 by worldwide meta-analysis. medRxiv preprint, version posted March 12, 2021. doi. org/10.1101/2021.03.10.21252820

[99] Thieme H. Lower Palaeolithic hunting spears from Germany. Nature 1998; 385: 807-810

[100] Thieme H. Die Schöninger Speere. Mensch und Jagd vor 400.000 Jahren. Niedersächsisches Landesamt für Denkmalpflege. Stuttgart: Konrad Theiss Verlag, 2007

[101] Vespasiani DM, Jacobs GS, Brucato N, et al. Denisovan introgression has shaped the immune system of present-day Papuans. bioRxiv preprint, posted August 7, 2020. doi.org/10.1101/2020.07.09.196444

[102] Vernot B, Akey JM. Resurrecting surviving Neandertal lineages from modern human genomes. Science 2014; 343: 1017-1021

[103] Vernot B, Tucci S, Kelso J, et al. Excavating Neandertal and Denisovan DNA from the genomes of Melanesian individuals. Science 2016; 352: 235-239

[104] Vernot B, Zavala El, Gómez-Olivencia A, et al. Unearthing Neandertha population history using nuclear and mitochondrial DNA from cave sediments. Science 2021; 372: 590 
[105] Warren M. Biggest Denisovan fossil yet spills ancient human's secrets. Nature 2019; 569: 16-17

[106] White T, Suwa G, Asfaw B. Australopithecus ramidus, a new species of hominid from Aramis, Ethiopia. Nature 1994; 371: 306-312; Corrigendum: Nature 1995; 375: 88

[107] Wilkins J, Schoville B], Pickering R, et al. Innovative Homo sapiens behaviours 105,000 years ago in a wetter Kalahari. Nature 2021; 592 : 248-252

[108] Wood B, Harrison T. Review. The evolutionary context of the first hominins. Nature 2011; 470: 350-357

[109] Wood BA, David B. Patterson DB. Paranthropus through the looking glass. PNAS 2020; 117: 23202-23204

[110] Yair S, Lee KM, Coop G. The timing of human adaptation from Neanderthal introgression. Genetics 2021; 218: iyab052

[111] Zeberg H, Kelso J, Pääbo S. The Neandertal progesterone receptor. Mol Biol Evol 2020; 37: 2655-2660

[112] Zeberg H, Dannemann M, Sahlholm K, et al. A Neanderthal sodium channel increases pain sensitivity in present-day humans. Curr Biol 2020; 30: 3465-3469

[113] Zeberg H, Pääbo S. The major genetic risk factor for severe COVID-19 is inherited from Neanderthals. Nature 2020; 587: 610-612

[114] Zeberg H, Pääbo S. A genomic region associated with protection against severe COVID-19 is inherited from Neandertals. PNAS 2021; 118: e2026309118

[115] Zilhão J, Pettitt P. On the new dates for Gorham's Cave and the late survival of Iberian Neanderthals. Before Farming 2006: 3: 1-9
[116] Wranham R, Camody R. Human Adaptation to the Control of Fire. Evolutionary Anthropology 2010; 19: 187-199

[117] Martinón-Torres M, d'Errico F, Santos E, et al. Petraglia MD. Earliest known human burial in Africa. Nature 2021; 593: 95-100

[118] Schrenk F, Bromaget TG, Betzlert CG, et al. Oldest Homo and Pliocene biogeography of the Malawi Rift. Nature 1993; 365: 833-836

[119] Wood BA. Origins and evolution of the genus homo. Nature 1992; 355: 783-790

[120] Stringer C. The Status of Homo heidelbergensis. Evolutionary Anthropology 2012; 21: 101-107

[121] Haeckel E. Systematische Phylogenie der Wirbeltiere,Teil 3. Berlin: Georg Reimer Verlag; 1895

[122] Huerta-Sánchez E, Jin X, Asan. Altitude adaptation in Tibetans caused by introgression of Denisovan-like DNA. Nature 2014; 512: 194-197

[123] Huerta-Sánchez E, Casey FP. Simultaneous Viral Exposure and Protection from Neanderthal Introgression. Cell 2018; 175: 306-307

[124] Enard D, Petrov DA. Evidence that RNA Viruses Drove Adaptive Introgression between Neanderthals and Modern Humans. Cell 2018; 175: $360-371$

[125] Barras C. Story of most murderous people of all time revealed in ancient DNA. New Scientist 30.3.2019; 3223 https://www.newscientist. com/article/mg24132230-200-story-of-most-murderous-people-ofall-time-revealed-in-ancient-dna/; abgerufen am 31.5.2020

[126] Aubert M, Lebe R, Oktaviana AA et al. Earliest hunting scene in prehistoric art. Nature 2019; 576: 42-46 